\title{
Intranasal Nanoparticulate Systems as Alternative Route of Drug
}

Areen Alshweiata, ${ }^{\mathrm{a}, \mathrm{B}}$ Rita Ambrus ${ }^{\mathrm{a}}$ and Ildikó Csóka ${ }^{\mathrm{a}}$

${ }^{a}$ Faculty of Pharmacy, Institute of Pharmaceutical Technology and Regulatory Affairs, University of Szeged, Szeged, Hungary.

${ }^{b}$ Faculty of Pharmaceutical Science, The Hashemite University, Zarqa, Jordan.

Corresponding authors

Areen Alshweiat

Faculty of Pharmacy, Institute of Pharmaceutical Technology and Regulatory Affairs, University of Szeged

H- 6720, Eötvös u. 6. Szeged, Hungary. Tel+36702227752, Fax +366254557

Email areen.alshweiat@hu.edu.jo

\begin{abstract}
There is always a need for alternative and efficient methods of drug delivery. The nasal cavity can be considered as a non-invasive and efficient route of administration. It has been used for local, systemic, brain targeting, and vaccination delivery. Although many intranasal products are currently available on the market, the majority is used for local delivery with fewer products available for the other targets. As nanotechnology utilization in drug delivery has rapidly spread out, the nasal delivery has become attractive as a promising approach. Nanoparticulate systems facilitate drug transportation across the mucosal barrier, protect the drug from nasal enzyme degradation, enhance the delivery of vaccines to the lymphoid tissue of the nasal cavity with an adjuvant activity, and offer a way for peptide delivery into the brain and the systemic circulation, in addition to their potential for brain tumor treatment. This review article aims at discussing the potential benefit of the intranasal nanoparticulate systems, including nanosuspensions, lipid and surfactant, and polymer-based nanoparticles as regards productive intranasal delivery. The aim of this review is to focus on the topicalities of nanotechnology applications for intranasal delivery of local, systemic, brain, and vaccination purposes during the last decade, referring to the factors affecting delivery, regulatory aspects, and patient expectations. This review further identifies the benefits of applying the Quality by Design approaches $(\mathrm{QbD})$ in product development. According to the reported studies on nanotechnology-based intranasal delivery, potential attention has been focused on brain targeting and vaccine delivery with promising outcomes. Despite the significant research effort in this field, nanoparticle-based products for intranasal delivery are not available. Thus, further efforts are required to promote the introduction of intranasal nanoparticulate products that can meet the requirements of regulatory affairs with high patient acceptance.
\end{abstract}

Keywords: Intranasal, nanoparticulate system, drug delivery, Quality by Design, regulatory, patients' expectations. 


\section{INTRODUCTION}

Clear evidence of the nasal cavity as an effective route of administration has attracted research groups to concentrate on exploiting this region as an alternative means for systemic and brain delivery of drugs and vaccines to overcome the inconvenience of already available routes.

Over the past decades, nanotechnology has gained an advanced position in drug delivery approaches. A nanoparticulate system holds a great value over the manipulative characteristics of the applied therapeutics, such as solubility, permeability, and halflife. These features allow the extended use of nanoparticulates for cancer targeting and controlled release purposes. Many parenteral, oral, and topical nanoparticulate therapeutics are available on the market and clinical trial stages [1-8].

The term nanotechnology is also widely used and defined as the control and manipulation of matter at the nano-scale (10-100 $\mathrm{nm})$. However, the particles within the size range of 1-1000 $\mathrm{nm}$ are considered as nanoparticles in practice. Nanoparticles are regarded as special due to the fact that particles on the nanometer scale have unique optical, electronic, and structural/functional properties distinctive from the normal size. Moreover, higher permeability, a large surface to volume ratio, and higher mucoadhesion can be achieved as a consequence of nanosizing [9-13].

Nanosystems form a special group regarding their regulatory acceptance. Related guidelines and relevant chapters of the European Medicines Agency (EMA) and the Food and Drug Administration (FDA) must be applied during all manufacturing stages from material selection and formulation to the final production. Furthermore, the FDA has emphasized the application of the Quality by Design (QbD) methodology, which can be especially useful for novel, high risk dosage forms and administration routes. The adoption of the International Council on Harmonization (ICH) guidelines for pharmaceutical development-Q8, risk management-Q9 and quality system-Q10 provides great potential for careful planning during the formulation and development even in the early phase of the research [14-20].

A high number of successful applications of nanoparticulate systems in drug delivery motivated to apply this technology in the case of the intranasal route; in order to improve drug delivery and to overcome the limits of this administration route. A combination of novel nanotechnology developments together with increased knowledge on intranasal delivery can efficiently lead to substantial advances in drug delivery with enhanced bioavailability and patient acceptance.

\section{NASAL CAVITY}

\subsection{Nasal Anatomy}

As known from anatomy studies, the human nasal cavity (Fig $\mathbf{1}$ ) is composed of two symmetrical chambers (nostrils) separated by the median septum, the area inside each chamber is divided into the nasal vestibule area and the main nasal cavity containing the respiratory and olfactory regions. The total surface area and volume of the nasal cavity are $150 \mathrm{~cm}^{2}$ and $15 \mathrm{ml}$, respectively $[21,22]$.

The nasal respiratory area is the largest part of the nasal cavity, it is confined between the septal and lateral walls and it contains the superior, middle, and inferior turbinates forming the slit-like area that is responsible for the humidification and temperature regulation of the inspired air [23].

The uppermost region of the nasal cavity is the olfactory region, which is responsible for the sense of smell. This area comprises $10 \%$ of the total intranasal cavity and the olfactory information is sent from the olfactory bulb via the olfactory neuron into the piriform cortex, amygdala, and entorhinal cortex; where this can promote direct brain transport $[24,25]$.

The cell lining type varies along the nasal cavity; the vestibules are covered by non-ciliated squamous and transitional epithelium with poor blood perfusion, whereas the respiratory region is covered by epithelium consisting of ciliated, pseudostratified, and columnar epithelium cells with a rich blood supply from the underlying lamina propria. The presence of microvilli along with columnar cells intensifies the surface area available for drug absorption, as each cell covered with 300 microvilli, and their fine projections (cilia) are fundamental to mucus transport into the nasopharynx. The topographical and physiological features of the respiratory region are responsible for being the main region for permeation. Similar to the respiratory area, the olfactory region is covered by pseudostratified epithelium with a specialized refractory receptor for smell perception. Prior to transfer, the olfactory component must be dissolved in the serous fluid that is produced and secreted by Bowman's gland [26-29]. 
Besides the significance of the respiratory region for systemic absorption, it plays a crucial role in direct drug delivery into the brain through the trigeminal region. The olfactory and trigeminal structures act as the only available apertures of the central nervous system (CNS) entry [30].

The anatomical aspect plays a crucial role in nasal delivery. To get the benefit of the high surface area of the nasal cavity and its consequences on higher absorption, the formulation must be spread over a large mucosal area. The place of distribution inside the cavity is essential for the activity; for example, for local delivery, systemic delivery, and vaccines, broad distribution is required whilst in brain targeting the drug must be delivered into the upper parts of the nose containing the olfactory region in addition to covering the trigeminal nerve, which may have a contribution in targeting. Such factors must be considered in selecting the dosage form and designing the delivery devices to ensure the proposed deposition and coverage of the formulation to get the intended response [31,32].

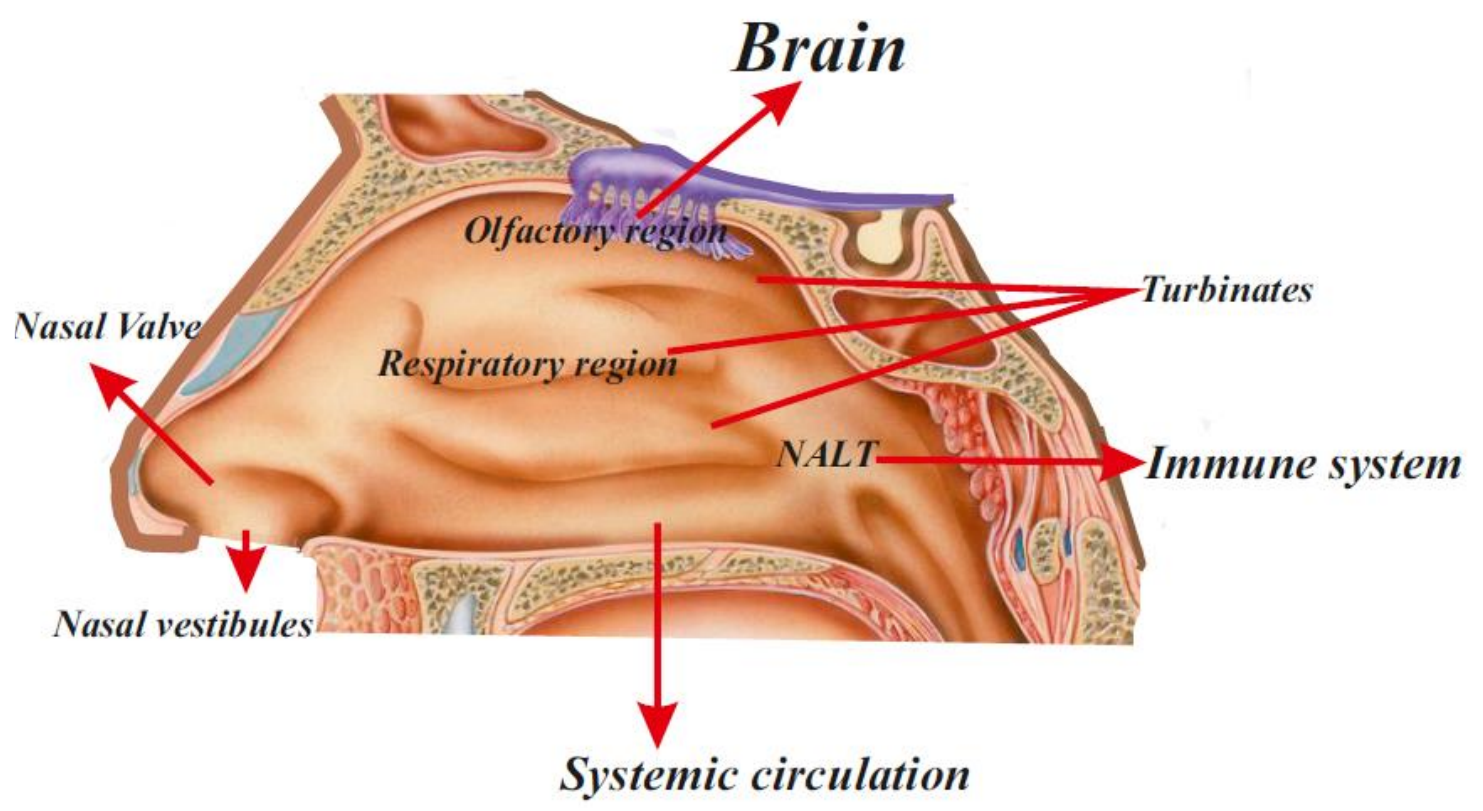

Fig. (1). Anatomical structure of the human nasal cavity.

\subsection{Nasal Cavity as Drug Route of Administration}

The distinction of the intranasal route is ascribed mainly to the anatomical and physiological characteristics of the nasal cavity. The nasal cavity offers a number of advantages, such as: avoiding first-pass metabolism, high surface area, high permeation, high vascularization, and having a nose to brain direct pathway as well as circumventing the blood brain barrier. Thus, the nasal route has the potential for the delivery of drugs that suffer from extensive first-pass metabolism, poor solubility, and degradation in the gastrointestinal tract. It is also an attractive site for vaccine and peptide delivery that have been parenterally administered so far. The intranasal route is a non-invasive, non-sterile, and easily administered method that can enhance patients' compliance [33-39].

On the other hand, many limitations could adversely affect nasal delivery, these include: mucociliary clearance, restricted volume of nasal administration (max. $200 \mathrm{ul}$ ), presence of enzymes and efflux transporters, pathological and environmental factors that affect intranasal blood supply. Moreover, the narrow nasal valve represents a potential obstacle to an efficient drug delivery [40-43].

\subsection{Emerging Intranasal Application from Local to Systemic, Brain, and Vaccine Delivery}

The intranasal delivery of drugs has been initially utilized for the local treatment of topical conditions. Various marketed drugs have been used to treat congestion, nasal allergies, infections, and nasal polyps. Decongestants, steroids, and antihistamines are the most common drugs that are nasally applied for their local action [44-48]. 
As a consequence of the previously mentioned advantages, the nasal cavity has evolved from local administration into a route for systemic, brain targeting, and vaccine delivery. This extension has opened up the possibilities for all drug delivery purposes, including cancer treatment [49-53].

Intranasal products with systemic effects are commercially available for certain drugs such as zolmitriptan, sumatriptan, ergotamine, butorphanol tartrate, and fentanyl as well as peptides such as calcitonin, desmopressin, buserelin, and nafarelin [54-61]. Other drugs have been nasally introduced for the treatment of urgent conditions such as migraine, seizures, opioid overdose, and pain breakthrough in cancer [62-67].

Maximum 2\% of drugs are capable of reaching the brain after systemic administration due to the presence of the protective brain capillary endothelium. The exploitation of the intranasal route to target the CNS is an attractive approach to circumvent the blood brain barrier (BBB) and deliver the drug directly through the cribriform plate, olfactory and trigeminal regions. Alzheimer's disease, depression, migraine, schizophrenia, HIV consequences, and multiple sclerosis are all CNS diseases that systemic administration has failed to treat. The availability of an effective delivery rather than the drugs was the missing part for achieving considerable therapeutic outcomes [68-70].

The intranasal cavity offers easy administration for vaccines, inducing both mucosal and systemic immunity. The importance of this site has evolved from the nature of infections itself since the majority of viral and bacterial infections start from the mucosal tissues. Both innate and adaptive immune responses can be directly initiated after the delivery of the antigen via nasalassociated lymphoid tissues (NALT) through the distinctive M cells into the antigen sampling cells, dendritic cells, B-cells, and T-cells, being responsible for the humoral immune responses mediated by secretory IgA antibodies [71-74]. The pharmaceutical aspects of intranasal vaccination have been thoroughly discussed by Sharma et al. [75].

\section{NANOTECHNOLOGY AS A FURTHER ASPECT OF THE INTRANASAL DELIVERY OF DRUGS}

\subsection{Rationale for using Nanotechnology for Intranasal Delivery}

Within the last decades, tremendous efforts have focused on intranasal delivery and its potential for different applications beyond its local importance; to achieve systemic delivery and brain targeting in addition to mucosal and systemic vaccination.

Hypothetically, the ideal route is available. Nevertheless, many limitations can hamper its efficiency. The combination of nanotechnology as the drug preparation method and intranasal delivery as the route is supposed to provide an effective delivery system. Nanotechnology offers the criteria for achieving high solubility and dissolution rates, which are the key factors for drug absorption and activity. Furthermore, this technology can protect the drugs from nasal enzyme activity, counteract the mucociliary action to increase contact time and promote permeation. Table $\mathbf{1}$ lists the nanotechnology effects on the major nasal delivery limitations and Table $\mathbf{2}$ identifies the rationale for using the nasal passage as a route for administration and nanoparticles as a technology for various targets. Many risks can also be increased, such as toxicity or even the inhalation of the nano-scale particles. Thus the identification of the risks associated with the intranasal delivery of nanoparticles must be cautiously evaluated [76-78]

Table 1. Nanotechnology solutions for intranasal delivery limitations.

\begin{tabular}{|l|l|l|}
\hline \multicolumn{1}{|c|}{ Limitation } & \multicolumn{1}{|c|}{ Nanotechnology effects } & Refs \\
\hline \hline Poor drug solubility & $\begin{array}{l}\text { High ratio of surface area to volume } \\
\text { Interactions between the groups of the polymer and drug molecule, such as } \\
\text { electrostatic, and H-bonding } \\
\text { Production of a microenvironment with special lower polarity inside the } \\
\text { nanoparticles than in the aqueous bulk phase }\end{array}$ & $\begin{array}{l}{[79-} \\
83]\end{array}$ \\
\hline $\begin{array}{l}\text { Mucociliary clearance and short } \\
\text { residence time }\end{array}$ & $\begin{array}{l}\text { Localization of the formulation for a longer time } \\
\text { Enhancement of contact time inside the nasal cavity }\end{array}$ & $\begin{array}{l}{[84-} \\
86]\end{array}$ \\
\hline $\begin{array}{l}\text { Poor penetration for large and } \\
\text { hydrophilic molecules }\end{array}$ & $\begin{array}{l}\text { Ability to open up tight junctions } \\
\text { Possibility of high endocytosis } \\
\text { Ability to change mucosal membrane properties }\end{array}$ & {$[87,88]$} \\
\hline Enzymatic activity & Encapsulation of liable molecules & {$[89]$} \\
\hline P-glycoprotein efflux transporter & Efficiency for bypassing and inhibition of P-glycoprotein & {$[90,91]$} \\
\hline
\end{tabular}


Table 2. Rationale for the use of the nasal route and nanoparticulate systems with various targets.

\begin{tabular}{|l|l|l|}
\hline Target & $\begin{array}{l}\text { Rationale for nasal } \\
\text { delivery }\end{array}$ & Rationale for using nanoparticulate systems \\
\hline Local & $\begin{array}{l}\text { Rapid onset of action } \\
\text { Minimum effective dose } \\
\text { Minimum side effects }\end{array}$ & Enhancement of contact time with mucosa \\
\hline Systemic & $\begin{array}{l}\text { Ease of administration } \\
\text { Rapid onset of action } \\
\text { Avoidance of first-pass } \\
\text { metabolism } \begin{array}{l}\text { Avoidance of gastric } \\
\text { deterioration and enzymatic } \\
\text { degradation }\end{array}\end{array}$ & $\begin{array}{l}\text { Delivery of peptide, proteins, and high molecular weight therapeutics } \\
\text { High systemic absorption }\end{array}$ \\
\hline Brain & $\begin{array}{l}\text { Circumvention of the blood } \\
\text { brain barrier } \\
\text { Noninvasive application of } \\
\text { anti-tumor agents }\end{array}$ & $\begin{array}{l}\text { Drug targeting } \\
\text { Delivery of peptide, proteins, and high molecular weight therapeutics }\end{array}$ \\
\hline Vaccination & $\begin{array}{l}\text { Noninvasive } \\
\text { Induction of mucosal and } \\
\text { systemic immunity }\end{array}$ & Adjuvant activity \\
\hline
\end{tabular}

\subsection{Pharmaceutical Factors of the Influence of Nanoparticles on Intranasal Delivery}

The pharmacokinetics and bioavailability of the applied drug (vaccine) are ruled by different factors related to the properties of both the active pharmaceutical agent (API) and the formulations. These factors determine the mechanism of absorption through the nasal mucosa [92].

Nanomaterials possess distinctive physicochemical properties compared to their conventional counterparts, and these properties provide nanoparticles with beneficial characteristics. The physicochemical characteristics of nanoparticles which most influence their administration through the nasal route include size, shape, chemical composition, physiochemical stability, crystal structure/polymorphism, surface area, surface charge, and surface energy in addition to drug loading and drug entrapment efficiency.

Particle size is a critical evaluation parameter to assess the desired properties of nanoparticles due to its consequences on surface area and viscosity, and thus drug dissolution, release, absorption, and stability [93]. Due to their small size, nanoparticles are usually used as a drug carrier via passive transport, active transport, and endocytosis [94,95]. However, the mechanism by which nanoparticles enhance drug transport is not fully described. Some studies considered that nanocarriers interact with the mucus layer and release the drug in the mucus or at the mucus-epithelial cell interface, while other studies implied that the drug-loaded nanoparticles themselves cross the mucosal barrier. Both cases involve the uptake of nanoparticles into the respiratory or olfactory epithelium and then drug payload diffused into the systemic circulation or to the CNS. Surface charge also plays an important role in the interactions of nanoparticles with biological systems. For example, positively charged nanoparticles have been designed to improve nasal adhesion with the nasal mucosa via the electrostatic interaction with the sialic groups of mucin [96]. Furthermore, it has also been observed that the surface charge of nanoparticles alters blood-brain barrier integrity and transmembrane permeability [95].

There is no clear trend found which is concerned with the influence of nanoparticle size on drug uptake into the tissue [97]. Therefore, the effect of these important factors on drug permeability has been discussed in many studies. Some authors studied the in vitro transport across nasal epithelium, ex vivo across nasal mucosa or in vivo with animal models. Brooking et al [98] studied the transport of 12'1-radiolabelled latex nanoparticles by using a range of particle sizes and surface coatings across rat nasal mucosa. Among 20, 100, 500, and $1000 \mathrm{~nm}$ of non-modified nanoparticles, the $20 \mathrm{~nm}$ sized particles showed the highest 
extent in the systemic circulation. The $20 \mathrm{~nm}$ sized nanoparticles showed 2-fold higher blood concentration than the $100 \mathrm{~nm}$ sized particles, while 500 and $1000 \mathrm{~nm}$ sized particles showed similar lower levels of uptake; half of these seen for the $100 \mathrm{~nm}$ sized particles. The surface modification of $100 \mathrm{~nm}$ sized particles changed the surface charge. This change had a significant effect on the uptake of the particles into the systemic circulation. Coating the particles with poloxamine 908 (-14 mV zeta potential) resulted in a significant reduction in uptake compared with the uncoated particles ( $-49 \mathrm{mV}$ zeta potential). However, coating of the polystyrene particles with Poly-I-lysine (PLL) (25 kDa) and PLL (I28 kDa) with zeta potentials +33 and +19 $\mathrm{mV}$, respectively, did not significantly change the levels of particles transported into the blood stream as compared to the uncoated particles despite these former particles had a positive surface charge. It is worth noting that these results contradicted what has been previously proved, namely that PLL is able to open the tight junction and increase the transport across the nasal membrane into the blood stream. It was expected that PLL-coated nanoparticles would give greater transport across the nasal membrane [99]. On the other hand, $100 \mathrm{~nm}$ chitosan modified particles resulted in a significant increase in the transport of particles into the blood stream due to its mucoadhesive effects and ability to open the tight junction.

Gartziandia et al [100] studied the transport of polymeric and lipid-based nanoparticles with the same surface charge $(-23 \mathrm{mV})$ across olfactory monolayers in rats. $100 \mathrm{~nm}$ sized nanostructured lipid carriers (NLCs) penetrated to a higher extent compared to the 220 poly(lactic-co-glycolic acid) (PLGA) nanoparticles. Moreover, the positively charged chitosan-coated NLCs increased the transcellular transport by almost threefold compared to the uncoated NLCs. Mistry et al [101] studied the transport of different-sized fluorescent carboxylated polystyrene nanoparticles across excised porcine olfactory epithelium mounted in a vertical Franz Diffusion Cell. 20, 100, and $200 \mathrm{~nm}$ of the non-modified nanoparticles (surface charge $-42 \mathrm{mV}$ ) were compared to Polysorbate 80-modified polystyrene nanoparticles $(-21 \mathrm{mV})$ and chitosan-modified nanoparticles $(+42 \mathrm{mV}$ surface charge). Polysorbate 80-coated (PEGylated) particles penetrated deeper in the tissue compared to the uncoated and chitosan-coated nanoparticles.

A study by Ahmad et al [102] discussed the effects of nanoemulsion (NE) particle size on the permanence of the NE within the nasal cavity. NEs with droplet size of $80,200,500$, and $900 \mathrm{~nm}$ were compared. The NEs were prepared from Labrafac $^{\circledR}$ WL1349/Labrafac ${ }^{\circledR}$ CC and Soluto ${ }^{\circledR}$. The results showed that the smaller the droplet size, the higher permanence within the nasal mucosa. The study also confirmed the translocation of $100 \mathrm{~nm}$ in the nasal mucosa and along the trigeminal nerve to the olfactory bulb. However, large nanodroplets $(900 \mathrm{~nm})$ were not transported to the olfactory bulb.

The shape of nanoparticles influences their stability, absorption, and cellular uptake. The spherical shape is the most stable thermodynamically. However, these effects are cross-linked with particle size and surface charge. Gratton et al [103] designed a series of particles with different sizes and shapes to study the interdependent effect of size and shape on their internalization by human cervical carcinoma epithelial (HeLa) cells. Nanoparticles and microparticles were prepared by using particle replication with non-wetting templates method. The particles were made of cationic, cross-linked poly(ethylene glycol) hydrogels. Three series were produced as follows: cubic-shaped particles $(2,3$, and $5 \mu m$ cube side length), cylindrical particles with identical heights but varying diameters ( 0.5 , and $1 \mu \mathrm{m}$ diameters), and cylindrical shaped nanoparticles $(100,150,200 \mathrm{~nm}$ diameters). The results showed a strong dependence of cellular internalization on the size and shape of the particles. $2 \mu \mathrm{m}$ cubic particles showed a significant internalization by the most cells, whereas 3 , and $5 \mu \mathrm{m}$ showed insignificant internalization. The cylindrical nanoparticles showed the same level of internalization, which was higher than the $2 \mu \mathrm{m}$ cubic particles. The cylindrical nanoparticles showed a very high degree of internalization. Moreover, it was found that $100 \mathrm{~nm}$ cylindrical particles were internalized to a lesser extent than the larger $150 \mathrm{~nm}$ cylindrical nanoparticles with the same ratio aspect. In another study, Chithrani et al [104] also used HeLa cells to investigate the intracellular uptake of spherical and rod-shaped gold nanoparticles. The results revealed that the uptake of rod-shaped nanoparticles was lower than that of their spherical counterpart. The difference in the surface chemistry between the two shapes could be one of the reasons for such uptake differences. However, the cellular uptake of rod-shaped structures with a lower aspect ratio (1:3) is greater than in the case of nanoparticles with a higher aspect ratio (1:5) although both of these rod-shaped gold nanoparticles were modified by cetyl trimethylammonium bromide.

Shi et al [105] developed a model to figure out the basic mechanisms for the uptake and release of nanoparticles in animal cells. The authors reported that there is an optimal particle size as well as an optimal shape for the maximum rate of particle absorption and release. Other studies showed the relationship between cellular uptake and nanoparticle size, shape, and surface chemistry, and the mechanism of cellular uptake were reported in literature [106-108]. The parameters affecting the loading and entrapment efficiency must be controlled to achieve a desirable and controlled release profile concerning the total amount 
of the released drug and the release kinetics. Accordingly, the amount of the loaded agent, the composition of the nanoparticle forming materials, the molecular weight of the constituents, the ratio of the active agent to the additives, concentration, and the type of the used stabilizing agents, and the manufacturing process parameters that can affect these properties must be investigated prior to preparation [109].

In addition to the pharmacokinetic properties, interaction with the mucosal tissue and the bioadhesive properties of the nanoparticles inside the nasal cavity are significant factors that can influence the delivery of the API. Mucus represents a challenge for drug delivery. The barrier properties of nasal mucus are related to the dense fiber network of mucin containing highly glycosylated (negatively charged) parts. Thereby, the way to increase interaction with mucus is by applying nanocarriers with a positive surface charge.

Another strategy has been used to modify the interactions with mucus; a way to produce mucus penetrating nanoparticles is by PEGylated modification of nanoparticle surfaces [110,111]. Many studies have identified and discussed the effects of PEG on nanoparticle transport across the nasal mucosa. For example, PEG-modified polylactide-polyglycolide (PLGA) nanoparticles for the tetanus toxoid showed higher antibody levels following the intranasal delivery than those corresponding to PLA unmodified nanoparticles. Moreover, the fluorescence microscopy studies revealed that the PEG-PLA particles were able to cross the rat's nasal epithelium to the brain [112]. Another study reported that PEGylated liposomes had shown greater uptake of risperidone into the brain in comparison to liposomes and cationic liposomes [113].

In conclusion, it is essential to characterize the nanomaterial properties and their interaction with the biological agent to produce successful nanoparticle systems and novel delivery.

This review shows the most common nanoparticulate systems intended for intranasal application with recent literature studies.

\section{NANOPARTICULATE SYSTEMS FOR NASAL DELIVERY}

\subsection{Intranasal Nanosuspensions/ Nanocrystals}

Nanosuspensions can enhance the dissolution rate and the saturation solubility of poorly water-soluble drugs. Nanosuspensions also offer the advantage of high drug loading capacity, and thus a possibility to introduce the required dose within the limited volume of the nasal cavity. Furthermore, small particles can penetrate the mucosal tissue more easily and are able to pass to the brain directly through the olfactory region, resulting in enhanced bioavailability [79,114].

The development of a nanosuspension for intranasal delivery for systemic purposes is demonstrated by Kürti et al [115]. In this study, a nanosuspension of meloxicam with $140 \mathrm{~nm}$ particle size has been prepared by co-milling with PVP-C30. The in vivo results showed the significant enhancement of the maximum plasma concentration $\left(\mathrm{C}_{\max }\right)$ and area under the curve (AUC) of the nasal meloxicam nanosuspension compared to the physical mixture (2.7-fold and 1.5-fold, respectively). The notable result was the tremendous differences in time required to reach $\mathrm{C}_{\max }\left(\mathrm{T}_{\max }\right) ; 5 \mathrm{~min}$ for the intranasal nanosuspension compared to 90 min for the oral administration with 1.6-fold higher $\mathrm{C}_{\max }$. These results ensured the efficacy of intranasal delivery to achieve a rapid onset of action close to intravenous (IV) administration. Another example showed the importance of a lyophilized nanosuspension (nanocrystals) for brain targeting of resveratrol with deacetylated gellan gum as an in situ ionic sensitive gelling agent. Intranasal delivery showed both brain $\mathrm{C}_{\max }$ and $\mathrm{AUC}_{0-\infty}$ higher than IV administration (2.3- and 2.88-fold, respectively). This study confirmed the direct transport of resveratrol into the brain with $458.2 \%$ drug targeting efficiency (DTE\%) and $78.18 \%$ brain drug direct transport (DTP\%) [116]. Whether resveratrol has been confirmed for Alzheimer's disease treatment or not, this study ensured a way for delivery and maximizing brain concentration where other routes failed to produce tangible evidence for brain targeting. Examples of recent intranasal nanosuspensions are listed in Table 3.

Table 3. Nanosuspension-based intranasal formulations.

\begin{tabular}{|c|c|c|c|c|c|}
\hline API & Target & Composition & Particle size & $\begin{array}{c}\text { Model/Compared } \\
\text { compartment }\end{array}$ & Observations \\
\hline \hline
\end{tabular}




\begin{tabular}{|c|c|c|c|c|c|c|}
\hline Carvedilol & Systemic & $\begin{array}{l}\text { Poloxamer } \\
407, \quad \text { oleic } \\
\text { acid, and } \\
\text { gellan gum }\end{array}$ & $190 \mathrm{~nm}$ & $\begin{array}{l}\text { Rabbits/ Oral } \\
\text { suspension and IV } \\
\text { solution }\end{array}$ & 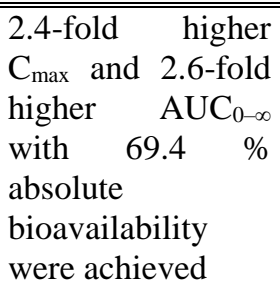 & $\begin{array}{l}{[117} \\
]\end{array}$ \\
\hline Meloxicam & Systemic & $\begin{array}{l}\text { Polyvinyl } \\
\text { alcohol, and } \\
\text { sodium } \\
\text { hyaluronate }\end{array}$ & $135 \mathrm{~nm}$ & $\begin{array}{l}\text { Rats/ Micronized } \\
(1.9 \mu m \text { particle } \\
\text { size }) \text { and raw } \\
\text { meloxicam spray }\end{array}$ & $\begin{array}{l}\text { 3-fold higher } \\
\text { plasma level was } \\
\text { observed after } 5 \\
\text { min }\end{array}$ & $\begin{array}{l}{[118} \\
]\end{array}$ \\
\hline Ezogabine & Brain & $\begin{array}{l}\text { Tween }^{\circledR} \quad 80, \\
\text { and } \\
\text { Poloxamer } \\
188\end{array}$ & $155-454 \mathrm{~nm}$ & $\begin{array}{ll}\text { Ex vivol Not } \\
\text { recorded }\end{array}$ & \begin{tabular}{lr}
\multicolumn{3}{l}{ Maximum } & $97.9 \%$ \\
of ezogabine \\
released within $6 \mathrm{~h}$ \\
and no cilio- \\
toxicity \\
observed
\end{tabular} & $\begin{array}{l}{[119} \\
]\end{array}$ \\
\hline
\end{tabular}

Studies on the nasal application of nanosuspensions reported an average size with the range 140-500 $\mathrm{nm}$. Moreover, the use of a mucoadhesive agent such as chitosan and the preparation of in situ gel are common procedures in the practice. Besides the systemic target, brain delivery has been significantly considered in the recent studies.

\subsection{Intranasal Lipid and Surfactant-Based Nanoparticulate Drug Delivery Systems}

Lipid nanoparticles show a promising approach for intranasal delivery. The advantages of active agent protection from enzymatic degradation, capability for hydrophilic as well as lipophilic molecule delivery, low toxicity, good permeability, and the possibility of modifications and adaptations have justified their wide application for the intranasal route. These systems include liposomes, solid lipid nanoparticles (SLN), nanostructured lipid carriers (NLC), niosomes, nanoemulsions (NE) and nanocapsules (NC) [120,121].

\subsubsection{Liposomes}

Liposomes are spherical vesicles containing one or more lipid bilayers that encapsulate aqueous drug compartments with a diameter in the range of $400 \mathrm{~nm}-2.5 \mu \mathrm{m}$. The properties of the lipid structure have a significant effect on the liposome surface charge, membrane flexibility, and the surface hydration and particle size [122]. These factors affect the kinetics of liposomes, bio-distribution, and faith after administration [123]. Liposome properties on uptake enhancement, and toxicity minimization were earlier explored by Kimelberg et al [124].

The intranasal delivery of liposomes showed an efficient delivery of calcitonin based on what has been discussed by Law et al. [125]. The effects of the type and charge of liposomes on calcitonin loading efficiency were verified; anionic liposomes showed higher loading efficiency than neutral and cationic ones. Loading efficiency increased with calcitonin concentration. The evaluation of the effects of calcitonin liposomes on bioavailability was accomplished with in vivo studies. The intranasal absorption of calcitonin was enhanced compared to the calcitonin solution; particularly, with positively charged liposomes, these findings confirmed the effects of different factors on the intranasal application of liposomes. The positively charged liposomes showed higher calcitonin bioavailability than the negative liposomes due to their higher contact time with the negatively charged mucosal membrane, thus lowering mucociliary clearance [126]. Alternatively, Chen et al [127] evaluated the usage of ultra-flexible liposomes on salmon's calcitonin intranasal absorption. There were no differences in the absorption between negative and positive liposomes, which was attributed to the rapid absorption of calcitonin from the liposomes. 
Insulin-loaded liposomes showed low permeability through the nasal mucosa in the rabbit model. On the other hand, the permeability of insulin entrapped in the liposomes was increased after using sodium glycocholate as a penetration enhancer $[128,129]$. The importance of liposomes for insulin delivery has been reported in the work of Jain et al [130]. The authors reported that chitosan-coated multiple vesicular liposomes were able to control the plasma glucose level in diabetic rats for two days. This sustained pattern can overcome the inconvenience of rapid increase followed by a rapid decline of insulin serum concentration after the intranasal administration. In spite of the feasibility of the intranasal use for sustained delivery, chronic application is controversial and to date, it is not practical [131].

The brain delivery of the intranasal liposomes has been investigated by using ovalbumin as a model peptide. Both transportation into brain and brain residence time have been enhanced compared to the solution preparation. In this study, cationic liposomes with an average size of $299 \mathrm{~nm}$ showed high loading efficiency and more than $90 \%$ drug delivery to the brain. Intranasal delivery depended on the concentration and volume of the administration in a pattern that smaller volumes of the liposomal preparation enhanced retention and reduced swallowing, thus promoting brain delivery [132].

Liposome contribution in intranasal mucosal vaccinations is related to the retention enhancement of the liposome inside the nasal cavity, therefore, the high chances of antigen delivery by M cells located on the NALT. Moreover, liposomes are able to induce immunoadjuvant activity [133,134]. Wong et al [135] showed that intranasal liposomes of hemagglutinin - the influenza antigen - induced serum the IgG levels higher than the naked antigen. Furthermore, modified liposomes showed enhanced delivery; for instance, chitosan-modified liposomes facilitated the interactions with the negatively charged mucosal surfaces and produced a great potential for DNA delivery. In another aspect, galactose-modified liposomes of ovalbumin showed a higher macrophage uptake and induced both mucosal IgA and serum IgG in a mouse model $[96,136]$. These findings highlighted the importance of modified liposomes in antigen delivery [137,138].

\subsubsection{Solid lipid nanoparticles (SLNs)}

Solid lipid nanoparticles are another example of lipid-based systems that have shown promising prospects for intranasal delivery. These systems are characterized by a 50-1000 nm range of particle size, they are composed of physiological lipids, and stabilized by nontoxic surfactants like Poloxamer and lecithin. The attractiveness of these systems is based on their safety compared to polymeric nanoparticles, and the low production cost compared to liposomes. They can be formulated by simple methods like high pressure homogenization and microemulsions [139]. Intranasal alprazolam-loaded SLN using Tween ${ }^{\circledR} 80$ and Pluronic ${ }^{\circledR}$ F68 had an average diameter of $99.5 \mathrm{~nm}$ and entrapment efficiency of $40.3 \%$. These SLNs showed higher brain bioavailability of alprazolam than with IV administration, with 55\% DTP and 224\% DTE. The intranasal SLN of budesonide showed higher permeation values than the free drug and the already marketed formulation of budesonide by 3.4- and 1.8-fold, respectively. [140,141]. In a study to prepare agomelatine SLNs with the emulsification solvent evaporation technique, the optimized SLN showed a particle size of $167 \mathrm{~nm}$, polydispersity index of 0.12 and entrapment efficiency of $91.3 \%$. This optimized formulation exhibited a substantial increase in each of the plasma peak concentration, the AUC (0-360 min) and the absolute bioavailability compared to those of the oral marketed dosage form with the values of $759.00 \mathrm{ng} / \mathrm{mL}, 7,805.69$ $\mathrm{ng} \cdot \mathrm{min} / \mathrm{mL}$ and $44.44 \%$, respectively. The SLN of agomelatine also revealed DTE of 190.02 and DTP of 47.37, thus higher brain targeting by the intranasal delivery than by the IV route [142].

\subsubsection{Nanostructured Lipid Carriers (NLCs)}

These systems, composed of both solid and liquid lipids as a core, offer the advantages of higher loading capacity than SLNs without undergoing polymorphic transition and drug explosion during storage [139]. Intranasal NLCs have been utilized for the brain targeting of temozolomide -an antitumor agent- in a recent study. In this study, NLC protected the drug from the p-gp system by the effects of Poloxamer 188, which also increased drug mucosal penetration. As a result, the brain concentration of temozolomide was higher than what has been achieved after IV administration with a sustained effect. Thus, it can provide a direct delivery for the treatment of brain tumors [143]. In another scope, the exceptional particle size, mucoadhesivity, and rapid release properties of tetrahydrocannabinol cationic NLC formulation raised the opportunity for the novel nasal spray to control cancer breakthrough pain [144]. 


\subsubsection{Niosomes}

Niosomes are structurally similar to liposomes in the concept of bilayer systems that entrap drugs with a chief difference in composition. Unlike liposomes, niosomes are composed of non-ionic surfactants that are responsible for a vesicle-like structure, thus providing more stability over liposomes by removing the inconvenience of oxidation and the purity variation of phospholipids [145]. The assembly of non-ionic surfactants into closed bilayers can be spontaneous or with the help of external stimuli, such as heat or shearing forces. Besides the activity of niosomes as hydrophilic and lipophilic drug carriers, they act as solubility enhancers, hence increasing the bioavailability of poorly water-soluble drugs. The main limitations of niosomes include aggregation, fusion, and leakages during storage. These adverse properties of niosomes can be minimized by additives such as cholesterol, fatty alcohols, charge inducers (dicetyl phosphate and stearylamine) or steric groups on the surface of niosomes [146].

Niosomes for intranasal application have been proposed to represent a promising approach for enhanced and controlled delivery. Intranasal folic acid niosomes intended for brain targeting have shown controlled ex vivo perfusion [147]. Regarding the systemic effects of intranasal niosomes, diltiazem-loaded niosomes have shown high half-life $\left(\mathrm{T}_{1 / 2}\right)$ and enhanced AUC $0-\infty$ with a reduced elimination rate; such prolonged action for diltiazem is of great value compared to its low oral bioavailability due to extensive first-pass metabolism [148]. The study of using intranasal niosomes for vaccination with glycoprotein B of herpes simplex virus type 1 has shown in vitro controlled release and in vivo elicited plasma glycoprotein antibodies (IgG) and systemic $\mathrm{T}$ helper cells [149]. These outcomes demonstrated the efficacy of niosomes to produce immunity against genital herpes in the female murine animal model and generalized the activity of niosomes for vaccination.

\subsubsection{Nanoemulsions (NEs)}

Nanoemulsions are part of a nanoparticulate system with a typical particle size of less than $200 \mathrm{~nm}$. These systems contain oil, water, and surfactants, and are characterized by simple preparation methods, biocompatible constituents, and robust stability against sedimentation, creaming, dilution, and temperature effects. NEs could enhance drug solubility and mucosal permeation [150]. Regarding their nature and the possibility for the addition of excipients, such as mucoadhesive and gel-forming polymers, NEs can provide a novel intranasal delivery system that meets the criteria of drug protection, mucosal adhesion, and permeation enhancement [151]. Intranasal NEs have been studied for their activity on systemic, brain targeting, and vaccine delivery, but not for local delivery due to the effect of absorption that would transfer the drug from the local site to the systemic circulation or even the brain. For example, intranasal nitrendipine NEs have shown a rapid onset of action with a relative bioavailability of $60 \%$ compared to the marketed oral tablets [152]. The preparation of NE in situ gel was proposed to be effective in enhancing systemic absorption based on the results of zaleplon; rapid absorption with $\mathrm{T}_{\max }$ of 20 min and 8-fold higher bioavailability compared to the marketed tablets. These results could be attributed to the effects of gel-forming polymers on residence time enhancement and permeation improvement [153].

The utilization of NEs in vaccine delivery has been receiving focused attention in many studies. NEs may exhibit a strong and broad antimicrobial, antiviral, and antifungal activity and provide good adjuvant activity. Many studies have demonstrated the efficacy of NE-based mucosal vaccinations against many infections, particularly, influenza and respiratory syncytial viruses [154-158]. For example, a W805EC adjuvant NE with $400 \mathrm{~nm}$ globules successfully enhanced the immune humoral response in murine animal model [157]. A recombinant HIV gp120 antigen NE showed the mucosal adjuvant activity of the NE for multivalent HIV vaccines [156]. Moreover, Sun et al [159] reported the adjuvant activity of the NE against methicillin-resistant Staphylococcus aureus (MRSA). This study reported a novel NE containing MRSA recombinant protein with an average diameter particle size of approximately $31 \mathrm{~nm}$. The mucosal vaccine showed improved immune responses without using additional adjuvant additives.

\subsubsection{Nanocapsules (NCs)}

Nanocapsules are composed of an oily core surrounded by a polymeric coat (shell) with a general range of particle sizes of 100-500 nm. NCs have been one of the systems in the focus of research due to their promising potential as an effective drug delivery platform for the transmucosal administration of peptides, vaccines, and hydrophilic and lipophilic drugs. The development of NCs has emerged from the ability to control particle size, surface properties, and composition. Therefore, control over stability and interaction with the mucosal membranes are attainable [160].

Importance has been given to the systemic delivery of intranasal peptides using NCs by the work of Prego et al [161]. In this study, salmon calcitonin was used as the model peptide and was incorporated into the chitosan-coated oil NCs. The results 
showed that NCs with sizes in the range of 200-570 nm led to hypocalcemic effects that were considerably enhanced and prolonged compared to the corresponding salmon calcitonin nanoemulsion or to the aqueous solutions with chitosan.

Sallam et al [162] developed a locally acting nasal delivery system of triamcinolone acetonide using different nanosystems. The NCs composed of a Capryol ${ }^{\circledR}$ oily core and Eudragit RS100 provided the highest mucosal retention compared to the NEs and NLCs with the least permeation, thus the drug was retained on the nasal mucosa. Moreover, NCs also showed lower mucosal irritation and superior stability compared with NEs. The identification of the intranasal NCs as a brain delivery approach has been discussed in different studies. For example, Clementino et al [163] reported the NC systems for brain delivery of simvastatin. The drug was loaded in lecithin/chitosan and the system was characterized by a particle size of $200 \mathrm{~nm}$, encapsulation efficiency of $98 \%$, and zeta potential of +48 . These NCs showed that around $20 \%$ of the dose was accumulated in the brain whilst the drug nanosuspension distributed the drug into other body organs and a very limited amount in the brain.

Vicente et al [164] reported a remarkable example for using NCs in the nasal system for the co-delivery of viral proteins and imiquimod for vaccination purposes. In this study, imiquimod, a lipophilic immunostimulant, was added in the oily core whilst the recombinant hepatitis B surface antigen (HB) was associated with the chitosan shell. The system showed a particle size of around $200 \mathrm{~nm}$, zeta potential of $+45 \mathrm{mV}$, and antigen association efficiency of $70 \%$. As a result, the NCs containing imiquimod elicited a protective immune response and showed increased $\operatorname{IgG}$ levels and specific immunological memory. Moreover, a balanced cellular/ humoral response was achieved indicating the capacity of the NCs to modulate the systemic immune response upon nasal vaccination.

NCs are widely reported as NEs with mucoadhesive polymers. The advantages of NCs over conventional NEs were confirmed in many studies. For example, intranasal risperidone NE showed enhanced brain and plasma concentrations compared to the drug solution, and it was comparable to the IV injected formulations. However, the NE with chitosan (NCs) formulations showed a significantly higher $\mathrm{C}_{\max }$ and AUC in addition to higher brain targeting (approximately 2-fold higher DPT\%) [165] The same effects have been achieved with olanzapine. A mucoadhesive NE of olanzapine showed a higher brain $\mathrm{AUC}_{0-\infty}$ compared to a NE without mucoadhesive polymer and also showed a 2-fold higher brain bioavailability than the IV injected drug [166]. Recently, Colombo et al [167] investigated the brain delivery of an intranasal NE containing kaempferol for glioma cell targeting. This study showed the enhanced delivery effects of the chitosan-based mucoadhesive NE compared to the NE without chitosan. A mucoadhesive NE of zolmitriptan is another example that showed the enhanced brain permeation of zolmitriptan from a chitosan-based mucoadhesive NE. A 2.8-fold higher brain AUC $(0-8)$ compared to the IV and brain targeting parameters of 164.77 and 9.61 for DTE\% and DTP\%, respectively, were attained [168]. Other studies investigated hyaluronic acid for the development of mucoadhesive nasal NEs for brain delivery. For example, resveratrol and curcumin were formulated together into a lipidic NE using hyaluronic acid as the mucoadhesive agent. The NEs showed brain target ability in a manner of about 7- and 9-fold increase in brain $\mathrm{AUC}_{0-7 \mathrm{~h}}$ for resveratrol and curcumin, respectively [169].

Literature on lipid- and surfactant-based nanoparticles demonstrated the significance of these systems for nasal delivery. These systems were characterized as having a particle size in the range of 75-300 nm. However, the particle size was dramatically increased when proteins and peptides were loaded and when multilamellar vesicles were prepared as shown with the next tabulated examples. Several examples have shown the usage of gelling, mucoadhesive, functionalized polymers and other additives to ensure the nanoparticles' properties and efficiency. Therefore, the selection of the constituents and their concentrations is very valuable to get the attributed quality, safety, and efficacy [158]. Table 4 shows the recent researches of intranasal lipid nanoparticulate systems.

Table 4. Recent examples of intranasal lipid nanoparticulate systems.

\begin{tabular}{|c|c|c|c|c|c|c|c|}
\hline API & Target & Systems & Composition & Characterization & $\begin{array}{c}\text { Model/compa } \\
\text { red } \\
\text { parameter }\end{array}$ & Results & Ref. \\
\hline Acyclovir & Systemic & Liposomes & $\begin{array}{l}\text { DPPC, } \\
\text { PVP, and PEG } \\
600\end{array}$ & $\begin{array}{l}627.4 \mathrm{~nm} \text { and } 43.2 \% \\
\text { entrapment efficiency }\end{array}$ & Rabbits/IV & $\begin{array}{l}\text { The bioavailability of } \\
\text { acyclovir has been } \\
\text { increased to } 60 \%\end{array}$ & {$[170]$} \\
\hline
\end{tabular}




\begin{tabular}{|c|c|c|c|c|c|c|c|}
\hline Fexofenadine & Systemic & Liposomes & $\begin{array}{lr}\begin{array}{l}\text { DPPC, } \\
\text { DPPG, } \\
\text { chitosan }\end{array} & \end{array}$ & $\begin{array}{l}359 \mathrm{~nm} \text { and } 66.1 \% \\
\text { entrapment efficiency }\end{array}$ & Rat/ Oral & $\begin{array}{l}\text { Chitosan-coated } \\
\text { liposomes showed 5-fold } \\
\text { higher bioavailability } \\
\text { with slower release, } \\
\text { lower } \mathrm{C}_{\max } \text {, and } 1.3 \text {-fold } \\
\text { higher } \mathrm{T}_{1 / 2}\end{array}$ & [171] \\
\hline Risperidone & Brain & Liposomes & $\begin{array}{l}\text { Stearylamine and } \\
\text { MPEG-DSPE }\end{array}$ & $\begin{array}{l}90-100 \mathrm{~nm} \text { with 50- } \\
60 \% \quad \text { entrapment } \\
\text { efficiency }\end{array}$ & $\begin{array}{l}\text { Rats/ Pure } \\
\text { drug IV bolus }\end{array}$ & $\begin{array}{l}\text { PEGylated liposomes } \\
\text { had 2.3-fold higher brain } \\
\mathrm{C}_{\max }, 1.7 \text {-fold higher } \\
\mathrm{AUC}_{0-\infty}, 4 \text { times shorter } \\
\mathrm{T}_{\max } \text {, and } 2.6 \text { higher } \mathrm{T}_{1 / 2}\end{array}$ & {$[113]$} \\
\hline Rivastigmine & Brain & Liposomes & $\begin{array}{l}\text { Lecithin, DDAB, } \\
\text { and PEG-DSPE }\end{array}$ & $\begin{array}{l}478 \mathrm{~nm} \text { and } 48 \% \\
\text { entrapment efficiency }\end{array}$ & $\begin{array}{l}\text { Rabbits/ IN } \\
\text { drug solution }\end{array}$ & $\begin{array}{l}\text { The stealth liposomes } \\
\text { showed 1.6-fold higher } \\
\text { brain } \mathrm{C}_{\max } \text {, 5-fold longer } \\
\mathrm{T}_{\max } \text { 5.5-fold higher } \\
\mathrm{AUC}_{0-\infty} \text { and } 4.2 \text {-fold } \\
\text { higher plasma } \mathrm{AUC}_{0-\infty} \\
\text { compared to the IN drug } \\
\text { solution }\end{array}$ & {$[172]$} \\
\hline Donepezil & Brain & Liposomes & $\begin{array}{l}\text { CHOL, PEG, and } \\
\text { DSPC }\end{array}$ & $\begin{array}{l}102 \mathrm{~nm} \text { and } 84.9 \% \\
\text { entrapment efficiency }\end{array}$ & $\begin{array}{l}\text { Rats/ Oral, IN } \\
\text { free drug }\end{array}$ & $\begin{array}{l}\text { The liposomes showed } \\
\text { higher } \mathrm{C}_{\max } \text { for IN } \\
\text { delivery with reduced } \\
\mathrm{T}_{\max } \text { Moreover, } \\
\text { enhanced brain and } \\
\text { plasma bioavailability } \\
\text { were achieved as the } \\
\text { liposomes had shown 2- } \\
\text { fold higher plasma } \\
\text { AUC }{ }_{0-\infty} \text { 2-fold higher } \\
\mathrm{C}_{\max } \text {, and } 1.5 \text {-fold higher } \\
\text { brain AUC } \mathrm{C}_{0-\infty} \text { compared } \\
\text { to the IN free drug }\end{array}$ & [173] \\
\hline Astaxanthin & Brain & SLN & $\begin{array}{ll}\text { Stearic } & \text { acid, } \\
\text { Poloxamer } & 188, \\
\text { and lecithin } & \end{array}$ & $\begin{array}{l}213.2 \mathrm{~nm} \text { and } 77.4 \% \\
\text { entrapment efficiency }\end{array}$ & Rats/ IV SLN & $\begin{array}{l}\text { SLN showed 2-fold } \\
\text { higher brain level after } 1 \\
\text { h with lower blood level } \\
\text { compared to the IV } \\
\text { delivery }\end{array}$ & {$[174]$} \\
\hline Quetiapine & Brain & SLN & $\begin{array}{l}\text { glycerol } \\
\text { monostearate and } \\
\text { Span-80 }\end{array}$ & $\begin{array}{l}117.8 \mathrm{~nm} \text { with } 97.5 \% \\
\text { encapsulation } \\
\text { efficiency }\end{array}$ & $\begin{array}{l}\text { Rats/ Tail IV, } \\
\text { oral drug }\end{array}$ & $\begin{array}{l}\text { The in situ gel of } \\
\text { quetiapine } \\
\text { similar blood and brain } \\
\text { concentration as the IV } \\
\text { delivery of the drug, but } \\
\text { higher than the oral } \\
\text { delivery }\end{array}$ & [175] \\
\hline H102 Peptide & Brain & Liposomes & $\begin{array}{l}\text { EPC, PEG-DSPE, } \\
\text { and CHOL }\end{array}$ & $\begin{array}{l}112.2 \mathrm{~nm} \text { and } \\
71.35 \% \text { encapsulation } \\
\text { efficiency }\end{array}$ & $\begin{array}{l}\text { Rats/ IN drug } \\
\text { solution }\end{array}$ & $\begin{array}{l}\text { Liposomes effectively } \\
\text { delivered the peptide } \\
\text { into the brain. The } \\
\text { liposomes showed higher } \\
\text { H102 concentrations at } \\
\text { different brain regions } \\
\text { with the maximum } \\
\text { concentration being } \\
\text { identified in the } \\
\text { hippocampus }\end{array}$ & [176] \\
\hline $\begin{array}{l}\text { Galanthamin } \\
\text { e } \\
\text { hydrobromid } \\
\text { e }\end{array}$ & Brain & Liposomes & $\begin{array}{l}\text { PG, SPC, and } \\
\text { CHOL }\end{array}$ & $\begin{array}{l}112 \mathrm{~nm} \text { and } 83.6 \% \\
\text { encapsulation } \\
\text { efficiency }\end{array}$ & $\begin{array}{l}\text { Rats/ Oral drug } \\
\text { solution }\end{array}$ & $\begin{array}{l}\text { The flexible liposomes } \\
\text { showed 3.52-fold higher } \\
\mathrm{C}_{\max }, 3.36 \text {-fold higher } \\
\mathrm{AUC}_{0-\infty} \text { and } \mathrm{T}_{\max } \\
\text { shortened to half } \\
\text { compared to the orally }\end{array}$ & [177] \\
\hline
\end{tabular}




\begin{tabular}{|c|c|c|c|c|c|c|c|}
\hline & & & & & & administered drug & \\
\hline GDNF & Brain & Liposomes & $\begin{array}{l}\text { DOPC, } \quad \text { CHOL, } \\
\text { and stearylamine }\end{array}$ & $\begin{array}{l}194 \mathrm{~nm} \text { and } 95 \% \\
\text { loading efficiency }\end{array}$ & $\begin{array}{l}\text { Rat/GDNF } \\
\text { solution in } \\
\text { PBS }\end{array}$ & $\begin{array}{l}\text { The liposomes showed } \\
\text { 10-fold more GDNF } \\
\text { delivery than the PBS } \\
\text { with the same } \\
\text { neuroprotective efficacy }\end{array}$ & $\begin{array}{l}{[178,} \\
179]\end{array}$ \\
\hline Haloperidol & Brain & SLN & $\begin{array}{l}\text { GMS and Tween }{ }^{\circledR} \\
80\end{array}$ & $\begin{array}{lr}140 \quad \mathrm{~nm}, & 71 \% \\
\text { entrapment efficiency } \\
\text { and } 23 \% & \text { drug } \\
\text { loading } & \end{array}$ & $\begin{array}{l}\text { Rats/ IN drug } \\
\text { solution }\end{array}$ & $\begin{array}{l}\text { SLN showed } 3.6 \text {-fold } \\
\text { higher brain } \mathrm{C}_{\max } \text { and } \\
3.5 \text {-fold higher } \mathrm{AUC}_{0-\infty}\end{array}$ & [180] \\
\hline $\begin{array}{l}\text { Protein } \\
\text { antigen } \\
\text { HBsAg }\end{array}$ & $\begin{array}{l}\text { Vaccinatio } \\
\mathrm{n}\end{array}$ & Liposomes & $\begin{array}{l}\text { EPC, CHOL, and } \\
\text { PAA }\end{array}$ & $\begin{array}{l}773 \mathrm{~nm} \text { with } 53.3 \% \\
\text { encapsulation } \\
\text { efficiency }\end{array}$ & Mice/IM & $\begin{array}{l}\text { Gel core liposomes } \\
\text { induced serum and } \\
\text { mucosal immunity with } \\
\text { comparative serum IgG } \\
\text { to IM. Moreover, IN } \\
\text { induced significant SIgA } \\
\text { that IM failed to produce } \\
\text { with significant } 14^{\text {th }} \text { day } \\
\text { boosting }\end{array}$ & [181] \\
\hline $\begin{array}{l}\text { Lipopeptide- } \\
\text { based against } \\
\text { Group A } \\
\text { streptococcus }\end{array}$ & $\begin{array}{l}\text { Vaccinatio } \\
\mathrm{n}\end{array}$ & Liposomes & $\begin{array}{l}\text { DDAB, DPPC, } \\
\text { and CHOL }\end{array}$ & $\begin{array}{l}160 \mathrm{~nm} \text { and } 98 \% \\
\text { encapsulation } \\
\text { efficiency }\end{array}$ & $\begin{array}{l}\text { Mice/ IN } \\
\text { unmodified } \\
\text { peptide }\end{array}$ & $\begin{array}{l}\text { The prepared cationic } \\
\text { liposome containing the } \\
\text { lipopeptide induced both } \\
\text { mucosal and systemic } \\
\text { immunity and a high } \\
\text { level of titer after } 5 \\
\text { months' } \\
\text { immunization. } \\
\text { Furthermore, high IgG } \\
\text { and IgA titers were } \\
\text { measured }\end{array}$ & [182] \\
\hline OVA & $\begin{array}{l}\text { Vaccinatio } \\
\mathrm{n}\end{array}$ & Liposomes & $\begin{array}{l}\text { DOTAP and DC- } \\
\text { chol, CHOL }\end{array}$ & $57-846 \mathrm{~nm}$ & $\begin{array}{l}\text { Mice/ Nasal } \\
\text { naked OVA }\end{array}$ & $\begin{array}{l}\text { Liposomes were } \\
\text { prepared by using } \\
\text { DOTAP and DC-chol or } \\
\text { by DOTAP and CHOL. } \\
\text { The cationic liposomes } \\
\text { induced a Th2 immune } \\
\text { response with high levels } \\
\text { of IL-4 expressions with } \\
\text { adjuvant activity. } \\
\text { DOTAP/DC-chol induced } \\
\text { liposomes antigen-specific } \\
\text { potent antig } \\
\text { IgG serum responses that } \\
\text { were superior to } \\
\text { DOTAP/chol liposomes. } \\
\text { Moreover, the liposomal } \\
\text { activity was independent } \\
\text { of particle size }\end{array}$ & [183] \\
\hline DNA-hsp65 & $\begin{array}{l}\text { Vaccinatio } \\
\mathrm{n}\end{array}$ & Liposome & $\begin{array}{l}\text { EPC, DOTAP, } \\
\text { and DOPE }\end{array}$ & $\begin{array}{l}244.5,985.9 \mathrm{~nm}^{\mathrm{a}} \\
616.7,2749.6 \mathrm{~nm}^{\mathrm{b}}\end{array}$ & $\begin{array}{l}\text { Mice/IM } \\
\text { naked DNA }\end{array}$ & $\begin{array}{l}\text { Liposomes contained } \\
\text { DNA or were complexed } \\
\text { with the DNA on the } \\
\text { surface and produced a } \\
\text { significant reduction in } \\
\text { the number of bacilli in }\end{array}$ & [184] \\
\hline
\end{tabular}




\begin{tabular}{|c|c|c|c|c|c|c|c|}
\hline & & & & & & $\begin{array}{l}\text { the lungs with } 16 \text {-fold } \\
\text { reduction in the required } \\
\text { DNA amount. These } \\
\text { liposomes were cationic } \\
\text { with no toxic effects }\end{array}$ & \\
\hline $\begin{array}{l}\text { BSA as } \\
\text { model } \\
\text { antigen }\end{array}$ & $\begin{array}{l}\text { Vaccinatio } \\
\mathrm{n}\end{array}$ & Liposomes & $\begin{array}{l}\text { SPC, DMPG } \\
\text { CHOL, SA, and } \\
\text { alginate, chitosan, } \\
\text { and TMC }\end{array}$ & $\begin{array}{l}\text { 303-996.4 nm with } \\
60-69 \% \\
\text { encapsulation } \\
\text { efficiency }\end{array}$ & Ex vivo & $\begin{array}{l}\text { The particle size was } \\
\text { increased dramatically } \\
\text { after coating with } \\
\text { polymer. TMC amongst } \\
\text { others showed the best } \\
\text { mucoadhesive } \\
\text { capabilities. However, } \\
\text { the TMC-coated } \\
\text { liposomes showed a low } \\
\text { mucosal penetration due } \\
\text { to due to their high } \\
\text { particle size }\end{array}$ & [185] \\
\hline $\begin{array}{l}\text { Streptomycin } \\
\text { sulfate }\end{array}$ & $\begin{array}{l}\text { Brain and } \\
\text { systemic }\end{array}$ & SLN & $\begin{array}{l}\text { Compritol }^{\circledR} 888 \\
\text { ATO, Tween } \\
\text { and soy lecithin }\end{array}$ & $\begin{array}{l}140 \mathrm{~nm} \text { and } 54.8 \% \\
\text { entrapment efficiency }\end{array}$ & $\begin{array}{l}\text { Mice/ IN Free } \\
\text { drug }\end{array}$ & $\begin{array}{l}\text { Streptomycin-SLN } \\
\text { showed 3.15- and 11- } \\
\text { fold higher brain and } \\
\text { plasma concentrations } \\
\text { and less accumulation in } \\
\text { the kidneys, liver, and } \\
\text { spleen with 3.3, 12, and } \\
4 \text { times lower } \\
\text { concentrations, } \\
\text { respectively, being } \\
\text { observed }\end{array}$ & [186] \\
\hline $\begin{array}{l}\text { Rizatriptan } \\
\text { benzoate }\end{array}$ & Brain & SLN & $\begin{array}{l}\text { Lecithin, } \\
\text { Pluronic }{ }^{\circledR} \\
\text { and GMS }\end{array}$ & $\begin{array}{l}145-298 \mathrm{~nm} \text { and } 59- \\
80 \% \text { encapsulation } \\
\text { efficiency }\end{array}$ & 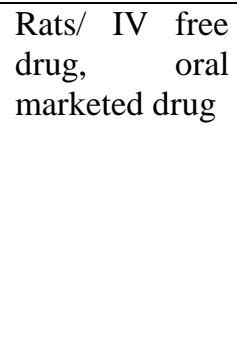 & $\begin{array}{l}\text { The optimized rizatriptan } \\
\text { SLN showed an } \\
\text { enhanced } \mathrm{T}_{1 / 2} \text { and higher } \\
\text { CSF concentrations by } \\
1.3 \text { - and 5.46-fold } \\
\text { compared to the IV and } \\
\text { oral, respectively. The } \\
\text { SLNs also showed a } \\
\text { shortened } \mathrm{T}_{\max }\end{array}$ & [187] \\
\hline Venlafaxine & Brain & NLC & $\begin{array}{ll}\text { Compritol }^{\circledR} & 888 \\
\text { ATO, } & \text { and } \\
\text { Capmul }^{\circledR} & \text { MCM }\end{array}$ & $\begin{array}{l}75 \mathrm{~nm} \text { and } 81.4 \% \\
\text { entrapment efficiency }\end{array}$ & Ex vivo & $\begin{array}{l}\text { NLC of the venlafaxine } \\
\text { showed a } 1.5 \text {-fold higher } \\
\text { flux and } 1.5 \text {-fold higher } \\
\text { diffusion coefficient } \\
\text { compared to the free } \\
\text { drug solution across the } \\
\text { goat's nasal mucosa }\end{array}$ & [188] \\
\hline Asenapine & Brain & NLC & $\begin{array}{l}\text { GM and oleic } \\
\text { acid }\end{array}$ & $\begin{array}{l}167.3 \mathrm{~nm} \text { and } 83.5 \% \\
\text { encapsulation } \\
\text { efficiency }\end{array}$ & $\begin{array}{ll}\text { Rats/ IN free } \\
\text { drug }\end{array}$ & $\begin{array}{l}\text { NLC showed a higher } \\
\text { brain concentration of } \\
\text { Asenapine compared to } \\
\text { the IV delivery for the } \\
\text { drug with 1.8- and 2.7- } \\
\text { fold } \mathrm{C}_{\max } \text { and AUC AU-24, } \\
\text { respectively, being } \\
\text { achieved. Moreover, } \\
\text { Asenapine showed } \\
276.7 \% \text { brain } \\
\text { bioavailability. There } \\
\text { were marked increases } \\
\text { of the antipsychotic } \\
\text { effects }\end{array}$ & [189] \\
\hline
\end{tabular}




\begin{tabular}{|c|c|c|c|c|c|c|c|}
\hline Olanzapine & Brain & $\mathrm{NC}$ & $\begin{array}{l}\text { poly( }(\varepsilon- \\
\text { caprolactone) and } \\
\text { Poly(MMA-b- } \\
\text { DMAEMA) }\end{array}$ & $\begin{array}{l}254.9 \mathrm{~nm} \text { and } 99 \% \\
\text { encapsulation } \\
\text { efficiency }\end{array}$ & $\begin{array}{l}\text { Rats/ } \\
\text { Olanzapine } \\
\text { solution }\end{array}$ & $\begin{array}{l}\text { The olanzapine-loaded } \\
\text { amphiphilic methacrylic } \\
\text { copolymer- } \\
\text { functionalized PCL NC } \\
\text { enhanced the amount of } \\
\text { the drug in the brain } \\
\text { (1.5-fold higher } \\
\text { compared to the drug } \\
\text { solution) }\end{array}$ & [190] \\
\hline Loratadine & Local & $\begin{array}{l}\text { Niosomes- } \\
\text { in situ gels }\end{array}$ & $\begin{array}{l}\text { CHOL, various } \\
\text { Span surfactants, } \\
\text { Carbopol }{ }^{\circledR} 934, \\
\text { and Poloxamer } \\
407\end{array}$ & $\begin{array}{l}266 \mathrm{~nm} \text { with } 89-97 \% \\
\text { drug content }\end{array}$ & Ex vivo & $\begin{array}{l}\text { Niosomes were } \\
\text { formulated into an in situ } \\
\text { gel and they showed a } \\
\text { high residence time and } \\
\text { sustained drug release. }\end{array}$ & [191] \\
\hline Melatonin & Systemic & Niosomes & $\begin{array}{l}\text { CHOL, Span 60, } \\
\text { and SDC }\end{array}$ & $\begin{array}{l}100 \mathrm{~nm} \text { and } 84-94 \% \\
\text { encapsulation } \\
\text { efficiency }\end{array}$ & $\begin{array}{ll}\text { Rats/ } & \text { IV } \\
\text { melatonin } & \\
\text { solution } & \end{array}$ & $\begin{array}{l}\text { SDC increased } \\
\text { encapsulation efficiency. } \\
\text { The niosomes of } \\
\text { melatonin with SDC } \\
\text { showed } \\
\text { bioavailability compared } \\
\text { to the IV delivery }\end{array}$ & [192] \\
\hline Quetiapine & Brain & $\mathrm{NE}$ & $\begin{array}{l}\text { Transcutol }{ }^{\circledR} \mathrm{P}, \\
\text { Capmul }^{\circledR} \mathrm{MCM} \text {, } \\
\text { PG, and Tween }{ }^{\circledR} \\
80\end{array}$ & $\begin{array}{l}144 \mathrm{~nm} \text { and } 91 \% \\
\text { drug content }\end{array}$ & $\begin{array}{l}\text { Rats/ IV pure } \\
\text { drug solution }\end{array}$ & $\begin{array}{l}\text { QTP-loaded NE showed } \\
\text { a } 267.89 \text { DTE\% and } \\
63.63 \text { DTP\%, thus the } \\
\text { superiority of brain } \\
\text { targeting. }\end{array}$ & [193] \\
\hline Tramadol & Brain & $\mathrm{NE}$ & $\begin{array}{lr}\text { IPM, } & \text { Soya } \\
\text { lecithin, } & \text { and } \\
\text { Poloxamer } & 188\end{array}$ & $\begin{array}{l}136.3 \mathrm{~nm} \text { and } 99.16 \% \\
\text { entrapment efficiency }\end{array}$ & $\begin{array}{lrr}\text { Mice/ } & \text { IV } & \text { and } \\
\text { nasal } & \text { drug } \\
\text { solution } & \end{array}$ & $\begin{array}{l}\text { Tramadol-loaded NE } \\
\text { enhanced } \\
\text { antinociception at most } \\
\text { measurement time points } \\
\text { compared to the nasal } \\
\text { and IV solution. } \\
\text { Moreover, NE showed } \\
116.89 \text { DTE\% and } 98.06 \\
\text { DTP\% parameters. }\end{array}$ & [194] \\
\hline Quercetin & Brain & $\mathrm{NE}$ & $\begin{array}{l}\text { Oleic acid, PEG } \\
\text { 400, Tween }{ }^{\circledR} \quad 80, \\
\text { Labrasol }^{\circledR} \text {, and } \\
\text { Transcutol }^{\circledR} \text { HP }\end{array}$ & $\begin{array}{l}91.6 \mathrm{~nm} \text { and } 99.8 \% \\
\text { drug content }\end{array}$ & Rats/ IV NE & $\begin{array}{l}\text { Quercetin-NE improved } \\
\text { neurobehavioural } \\
\text { activity and reduced } \\
\text { infarction volume effects } \\
\text { in middle cerebral artery } \\
\text { occlusion. Moreover, } \\
4.8 \text {-fold higher brain } \\
\mathrm{C}_{\max } \text { and 5.3-fold higher } \\
\text { brain AUC } \mathrm{C}_{0-\mathrm{t}} \text {, } 9333.3 \% \\
\text { DTE, and } 2181.8 \% \mathrm{DPT} \\
\text { were achieved }\end{array}$ & [195] \\
\hline $\begin{array}{l}\text { Thymoquino } \\
\text { ne }\end{array}$ & Brain & $\mathrm{NE}$ & $\begin{array}{l}\text { Oleic } \\
\text { Carbitol }^{\mathrm{TM}}, \\
\text { Tween }^{\circledR} \\
\text { Labrasol }^{\circledR}, \\
\text { Cremophore EL }^{\circledR}\end{array}$ & $\begin{array}{l}94.8 \mathrm{~nm} \text { and } 99.9 \\
\text { drug content }\end{array}$ & $\begin{array}{ll}\begin{array}{l}\text { Rats/ } \\
\text { solution }\end{array} & \text { IV }\end{array}$ & $\begin{array}{l}\text { The mucoadhesive NE } \\
\text { improved } \\
\text { neurobehavioural } \\
\text { activity in middle } \\
\text { cerebral artery occlusion } \\
\text { and showed 628.6 DTE } \\
\text { and 90\% DTP brain } \\
\text { parameters } \\
\text { thymoquinone for }\end{array}$ & [196] \\
\hline
\end{tabular}




\begin{tabular}{|c|c|c|c|c|c|c|c|}
\hline $\begin{array}{l}\text { Saquinavir } \\
\text { mesylate }\end{array}$ & Brain & $\mathrm{NE}$ & $\begin{array}{l}\text { Capmul }^{\circledR} \quad \text { MCM, } \\
\text { Tween }^{\circledR} \quad 80, \text { and } \\
\text { PEG } 400\end{array}$ & $\begin{array}{l}176 \mathrm{~nm} \text { with } 96 \% \\
\text { drug content }\end{array}$ & Rats/ IV NE & $\begin{array}{lr}\text { NE showed } 2919.3 \\
\text { DTE\% and 96.6 DTP\%, } \\
\text { suggesting } \\
\text { targeting }\end{array}$ & [197] \\
\hline Sertraline & Brain & $\mathrm{NE}$ & $\begin{array}{lr}\text { Capmul }^{\circledR} & \text { MCM, } \\
\text { Tween }^{\circledR} & 80, \text { and } \\
\text { PEG } & \end{array}$ & $\begin{array}{l}78 \mathrm{~nm} \text { whilst the drug } \\
\text { content was not } \\
\text { recorded }\end{array}$ & Ex vivo & $\begin{array}{l}\text { Ex vivo showed a } 62 \% \\
\text { nasal absorption for } \\
\text { sertraline through a } \\
\text { goat's nasal mucosa } \\
\text { within } 4 \mathrm{~h}\end{array}$ & [198] \\
\hline TNF $\alpha$ siRNA & Brain & $\mathrm{NE}$ & 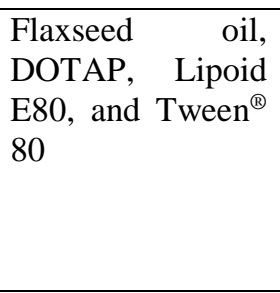 & $\begin{array}{l}\text { 69-166 } \mathrm{nm} \text { and } 70 \% \\
\text { encapsulation } \\
\text { efficiency }\end{array}$ & $\begin{array}{l}\text { Rats/ Naked } \\
\text { siRNA }\end{array}$ & $\begin{array}{l}\text { 5-fold higher brain } \\
\text { uptake and the NE of } \\
\text { TNF } \alpha \text { siRNA markedly } \\
\text { reduced the unregulated } \\
\text { levels of TNF } \alpha \text { in an } \\
\text { LPS-induced model of } \\
\text { neuroinflammation }\end{array}$ & [199] \\
\hline $\begin{array}{l}\text { OMP } \\
\text { antigen- } \\
\text { Burkholderia } \\
\text { cenocepacia } \\
\text { bacteria }\end{array}$ & $\begin{array}{l}\text { Vaccinatio } \\
\mathrm{n}\end{array}$ & $\mathrm{NE}$ & $\begin{array}{l}\text { The compositions } \\
\text { were not } \\
\text { recorded. } \\
\text { However, NE was } \\
\text { supplied by } \\
\text { BlueWillow } \\
\text { Biologics } \\
\text { (Michigan, USA) }\end{array}$ & Not recorded & $\begin{array}{l}\text { Mice/ OMP- } \\
\text { PBS }\end{array}$ & $\begin{array}{l}\text { OMP-NE-loaded antigen } \\
\text { elicited high OMP- } \\
\text { specific IgG antibodies } \\
\text { with response to booster } \\
\text { immunisation (13-30- } \\
\text { fold higher than OM- } \\
\text { PBS). Also a high rate of } \\
\text { pulmonary clearance of } \\
\text { bacteria was observed }\end{array}$ & [200] \\
\hline OVA antigen & $\begin{array}{l}\text { Vaccinatio } \\
\mathrm{n}\end{array}$ & $\mathrm{NE}$ & $\begin{array}{l}\text { Oleic } \quad \text { acid, } \\
\text { mannide } \\
\text { monooleate, and } \\
\text { Tween }{ }^{\circledR} 80\end{array}$ & $\begin{array}{l}153 \mathrm{~nm} \text { whilst the } \\
\text { content of the OVA } \\
\text { antigen was not } \\
\text { recorded }\end{array}$ & $\begin{array}{ll}\begin{array}{l}\text { Mice/ } \\
\text { antigen }\end{array} & \text { OVA }\end{array}$ & $\begin{array}{l}\text { Oleic acid NE showed } \\
\text { high IgA and serum IgG } \\
\text { for the } 45^{\text {th }} \text { day and } \\
\text { induced mucosal } \\
\text { immunity with single } \\
\text { booster immunization }\end{array}$ & [201] \\
\hline W805EC & $\begin{array}{l}\text { Vaccinatio } \\
\mathrm{n}\end{array}$ & $\mathrm{NE}$ & $\begin{array}{l}\text { NE was supplied } \\
\text { by BlueWillow } \\
\text { Biologics } \\
\text { (Michigan, USA) }\end{array}$ & $\begin{array}{l}424-774 \mathrm{~nm} \text { whilst } \\
\text { the content of the } \\
\text { W805EC was not } \\
\text { recorded }\end{array}$ & $\begin{array}{l}\text { Mice/Vaccine } \\
\text { in phosphate } \\
\text { buffer }\end{array}$ & $\begin{array}{l}\text { The NEs showed that } \\
\text { high hemagglutination } \\
\text { titers of serum and high } \\
\text { influenza-specific IgG } \\
\text { and IgA titers, also high } \\
\text { IgA levels in the } \\
\text { bronchoalveolar lavage } \\
\text { were achieved in } \\
\text { comparison to the } \\
\text { vaccine in the phosphate } \\
\text { buffer. However, NEs } \\
\text { with 1:6 ratio of } \\
\text { cationic-to-non-ionic } \\
\text { surfactants and } 450 \text { nm } \\
\text { globule size elicited } \\
\text { significantly higher } \\
\text { influenza-specific IgG } \\
\text { serum antibody titers } \\
\text { than any other } \\
\text { formulation }\end{array}$ & [202] \\
\hline $\begin{array}{l}\text { Recombinant } \\
\text { hepatitis B } \\
\text { surface } \\
\text { antigen } \\
\text { (HBsAg) }\end{array}$ & $\begin{array}{l}\text { Vaccinatio } \\
\mathrm{n}\end{array}$ & $\mathrm{NE}$ & $\begin{array}{l}\text { NE was supplied } \\
\text { by BlueWillow } \\
\text { Biologics } \\
\text { (Michigan, USA) }\end{array}$ & $\begin{array}{l}349 \mathrm{~nm} \text { whilst the } \\
\text { content of the HBsAg } \\
\text { was not recorded }\end{array}$ & $\begin{array}{l}\text { Mice/Antigen } \\
\text { in PBS }\end{array}$ & $\begin{array}{l}\text { Robust and sustained } \\
\text { systemic IgG, mucosal } \\
\text { IgA, and strong antigen- } \\
\text { specific cellular immune } \\
\text { responses were } \\
\text { observed. Moreover, this } \\
\text { vaccine induced a Th1 } \\
\begin{array}{l}\text { associated cellular } \\
\text { immunity }\end{array}\end{array}$ & {$[203]$} \\
\hline
\end{tabular}




\begin{abstract}
Abbreviations: DPPC, L- $\alpha$-dipalmitoylphosphocholine; CHOL, cholesterol; PVP, polyvinylpyrrolidone; PEG, polyethylene glycol; DPPG, 1,2-dipalmitoyl-sn-glycero-3-phosphoglycerol; DSPE-PEG, distearylphosphatidylethanolamine-mPEG; DDAB, Didecyldimethyl ammonium bromide; DSPC, 1,2-distearyl-sn-glycero-3-phosphocholine; EPC, egg phosphotidylcholine; PG, propylene glycol; SPC, Soya phosphatidylcholine; DOPC, dioleoylphosphatidylcholine; PBS, phosphate buffer saline; GMS, Glyceryl monostearate; PAA, poly acrylic acid; DOTAP,

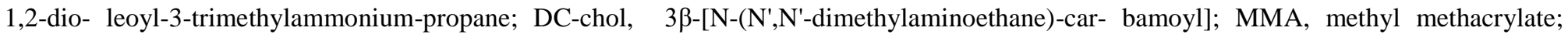
DMAEMA, 2-(dimethylamino)ethyl methacrylate; DOTAP, 1,2-dioleoyl-3-trimethylammonium-propane; DOPE, 1,2-dioleoyl-sn-glycero-3phosphoethanolamine; SPC, soy phosphatidylcholine; DMPG, phospholipid dimyristoyl phosphatidylglycerol; TMC, trimethyl chitosan; SDC, sodium deoxycholate; IPM, isopropyl myristate; LPS, lipopolysaccharide; GDNF, Glial cell-line derived neurotrophic factor; OVA, Ovalbumin; PBS, phosphate-buffered saline; IL-4, Interleukin 4; Th2, T helper cells 2; min, minutes; h, hour; IN, intranasal. Notes: ${ }^{\mathrm{a}}$ entrapping DNA-hsp65, ${ }^{\mathrm{b}}$ complexing DNA-hsp65

\subsection{Intranasal Polymeric-Based Systems}

Polymeric-based nanoparticles have become one of the most applied methods for drug delivery due to their characteristics of high drug loading, stability, and a variability of loading substances, including peptides, vaccines, and genes in addition to surface modification possibilities and the ability of controlled release. Polymeric-based nanoparticles include degradable and nondegradable polymers as well [204].
\end{abstract}

\title{
4.3.1 Biodegradable nanoparticles (BNPs)
}

Many polymers have been introduced for the intranasal delivery of nanoparticles like polysaccharides (chitosan); polyester derivatives, such as polylactic acid (PLA) and poly (lactide-co-glycolide) PLGA; proteins (Lectins); poly(ethylenimines); and poly(alkylcyanoacrylates). The selection of the proper type and modifications depend on many factors, such as encapsulation efficiency, particle size, and stability. Amongst these polymers, both chitosan and PGLA have been found to be the most promising. Both polymers are safe according to the FDA and are characterized by biocompatibility, biodegradability, and the ability for encapsulation of a wide range of hydrophilic, lipophilic, small, and large molecules with protection capabilities, in addition to the possibility of the modification to improve the BNPs properties and their interactions with the biological materials $[205,206]$.

The positive charge of the chitosan derivative is of high value for the intranasal delivery through increasing the contact time with the mucosal tissue. Its contribution in intranasal delivery has been proved via many types of research that have covered many aspects. Levodopa-chitosan-loaded nanoparticles were formulated as a thermoreversible gel for brain targeting. $74 \%$ of the drug was retained in the brain. However, gel formulation may hinder delivery due to its high viscosity and its effects on the ciliary beating [207,208].

Intranasal delivery of PLGA-tarenflurbil nanoparticles can prevent the elimination of this drug as a possible drug candidate for Alzheimer's treatment when its poor BBB penetration was responsible for its failure in phase III clinical trials [209]. Muntimadugu et al [210] showed that intranasal delivery of PLGA nanoparticles successfully targeted the brain with a 4-fold higher tarenflurbil brain concentration than with oral delivery and 1.5-fold higher than in the case of IV delivery. This study also showed the superiority of polymeric nanoparticles over SLNs in terms of loading efficiency and brain delivery. However, SLNs are still an option for direct drug to brain delivery.

The variability of nanoparticles to include mRNA possesses a great value for vaccination against tumors. The nasal delivery of cancer vaccination was tested by Phua et al [211] on mice. The results showed delayed tumor progression in both prophylactic and therapeutic models compared to the naked delivery. This effect can be attributed to the protection against enzymes and an efficient delivery as expressed by 24-hour-long luciferase expression. In the same field, Matsuo et al [212] reported the effect of ovalbumin- poly( $\gamma$-glutamic acid) nanoparticles. The results showed the activity of nanoparticles against E.G7-OVA tumor cells; tumor growth was suppressed and survival time was enhanced in mice models. Moreover, the inhibitory effect was extended to lung metastasis in a similar way as with subcutaneous (SC) injections. In another research, siRNA-loaded chitosan nanoparticles with $141 \mathrm{~nm}$ size and 81\% encapsulation capacity targeted Galectin 1 (Gal1), the potent immunosuppressive 
protein regulator in glioblastoma that induces the apoptosis of $\mathrm{T}$ cells and is the main contributor to glioblastoma resistance against temozolomide. The results showed a significant reduction of Gal 1 in both murine and human tumor cells with the subsequent reduction in Gal 1 mobility. The in vivo studies showed the applicability of the siRNA delivery to the brain via intranasal nanoparticles with a significant reduction of Gal 1. Chitosan offered the rapid attachment of the cells and protected the siRNA from RNAse degradation [213].

\subsubsection{Dendrimers}

Dendrimers are highly branched three-dimensional nanomaterials which have been introduced as drug carriers either via covalent conjugation with the drug molecule or drug (guest) hosting. These two options are attributed to their structure; they contain a large number of surface functional groups and a hydrophobic cavity that can enhance drug penetration through the mucosal membranes [214]. The advantages of dendrimers include internal cavity, particle size, and morphology control, in addition to their solubility enhancement, which allows the use of dendrimers for many drug formulations. Moreover, modified dendrimers have been targeted as nanomedicine against tumors, viral, and bacterial infection particles. Some of these products have been marketed successfully [215-218].

The first and most reported dendrimer type used in intranasal delivery was polyamidoamine (PAMAM). Kim et al [219] investigated using PAMAM as a siRNA gene carrier for the high mobility group box 1 (HMGB). The results of the reduced brain infraction volume were a proof for the activity of siRNA dendrimers as an efficient knock-down of HMGB [212]. In another study, the PAMAM formulation of haloperidol intended for brain targeting showed 100-fold higher solubility with significant brain and plasma concentrations, resulting in a 6.7-fold smaller dose being required to produce a response similar to the intraperitoneal (IP) injection [220]. Additionally, PAMAM showed substantial effects on the nasal absorption of poorly absorbed molecules, namely calcitonin, insulin, and fluorescein isothiocyanate-labelled dextran, as it was pointed out via in vivo studies using a rat model [221]. Both plasma concentration and AUC were increased. This study revealed a positive relationship between PAMAM molecular weight and its delivery enhancing effect. Beyond the benefits, toxicity is the major challenge for dendrimers. Toxicological effects are related to the generation number, concentration, contacting time, and is connected to their absorption enhancement capacity [222].

The application of dendrimers in intranasal delivery should be evaluated in regard to the host-guest relationship with paying attention to the guest properties, such as hydrophobicity and size for efficient binding or encapsulating. Furthermore, possible toxicity must be addressed cautiously [223,224].

According to the scientific literature, polymeric-based systems can meet the need for efficient intranasal delivery. Table $\mathbf{5}$ displays the most recent studies of these systems.

Table 5. Recent examples of intranasal polymeric-based nanoparticles.

\begin{tabular}{|c|c|c|c|c|c|c|c|}
\hline$\overline{\text { API }}$ & Target & $\begin{array}{c}\text { Syste } \\
\text { m }\end{array}$ & Composition & Characterization & $\begin{array}{c}\text { Model/compa } \\
\text { red } \\
\text { parameter }\end{array}$ & Observations & Refs \\
\hline $\begin{array}{l}\text { Olanzapin } \\
\mathrm{e}\end{array}$ & $\begin{array}{l}\text { Systemi } \\
\mathrm{c}\end{array}$ & $\overline{\mathrm{BNP}}$ & Chitosan and TPP & $\begin{array}{l}208-322 \quad \mathrm{~nm} \text { and } \\
87 \% \text { encapsulation } \\
\text { efficiency }\end{array}$ & $\begin{array}{ll}\text { Rabbits/ } & \text { IV } \\
\text { free drug } & \end{array}$ & \begin{tabular}{l}
\multicolumn{3}{l}{ Olanzapine-loaded } \\
chitosan showed $51 \%$ \\
absolute \\
and $\mathrm{T}_{\max }$ similavailability \\
\end{tabular} & [225] \\
\hline Donepezil & Brain & $\overline{B N P}$ & Chitosan and TPP & $150-200 \mathrm{~nm}$ & $\begin{array}{l}\text { Rats/ Free } \\
\text { drug } \\
\text { suspension }\end{array}$ & $\begin{array}{l}\text { Brain } \mathrm{C}_{\max } \text { and } \mathrm{AUC}_{0-\infty} \\
\text { were enhanced by } 3.7- \\
\text { and } 1.57 \text {-fold, } \\
\text { respectively. }\end{array}$ & [226] \\
\hline $\begin{array}{l}\text { Acetazola } \\
\text { mide }\end{array}$ & Brain & $\mathrm{BNP}$ & Chitosan and TPP & $153-277 \mathrm{~nm}$ & $\begin{array}{l}\text { Ex vivol Free } \\
\text { drug }\end{array}$ & $\begin{array}{l}\text { Maximum } 64 \% \\
\text { acetazolamide } \\
\text { released within } 4 \mathrm{~h} \text { and } \\
\text { no toxicity was observed }\end{array}$ & [227] \\
\hline
\end{tabular}




\begin{tabular}{|c|c|c|c|c|c|c|}
\hline $\begin{array}{l}\text { Olanzapin } \\
\mathrm{e}\end{array}$ & Brain & BNP & $\begin{array}{ll}\text { PLGA } & \text { and } \\
\text { Poloxamer } 407\end{array}$ & $\begin{array}{l}91 \mathrm{~nm} \text { and } 68.9 \% \\
\text { entrapment } \\
\text { efficiency }\end{array}$ & $\begin{array}{l}\text { Rats/ IV and } \\
\text { IN drug } \\
\text { solution }\end{array}$ & $\begin{array}{l}\text { The nanoparticles } \\
\text { showed brain } \\
\text { concentration } 6.35 \text {-fold } \\
\text { higher than the IV and } \\
\text { 10.86-fold higher than } \\
\text { the IN delivery of the } \\
\text { drug solution after } 3 \mathrm{~h}\end{array}$ \\
\hline Lorazepam & Brain & BNP & $\begin{array}{ll}\text { PLGA } & \text { and } \\
\text { Poloxamer } 407\end{array}$ & $\begin{array}{l}153.7 \mathrm{~nm} \text { and } 83.8 \% \\
\text { drug entrapment }\end{array}$ & $\begin{array}{l}\text { Rats/ IV and } \\
\text { IN free drug } \\
\text { solution }\end{array}$ & $\begin{array}{l}\text { Lorazepam-PLGA- } \\
\text { loaded NPs showed } \\
\text { higher brain/blood ratios } \\
\text { at all sampling time } \\
\text { points compared to the } \\
\text { delivery of the drug } \\
\text { solution }\end{array}$ \\
\hline Rotigotine & Brain & BNP & $\begin{array}{l}\text { PEG, PLGA, and } \\
\text { Lactoferrin }\end{array}$ & $\begin{array}{l}122 \mathrm{~nm} \text { and } 19 \% \\
\text { conjugation } \\
\text { efficiency }\end{array}$ & $\begin{array}{l}\text { Rats/ IN NPs- } \\
\text { PLGA }\end{array}$ & $\begin{array}{l}\text { The modified nontoxic } \\
\text { NPs } \\
\text { heterogeneous } \\
\text { distributions and higher } \\
\text { targeting than the } \\
\text { unconjugated NPs }\end{array}$ \\
\hline NT-I & Brain & BNP & $\begin{array}{l}\text { PLA and sodium } \\
\text { cholate }\end{array}$ & $\begin{array}{l}65 \mathrm{~nm} \text { and } 35.5 \% \\
\text { entrapment } \\
\text { efficiency }\end{array}$ & $\begin{array}{l}\text { Rats/ IV NPs- } \\
\text { PLGA and IV } \\
\text { of NT-I }\end{array}$ & $\begin{array}{l}\text { PLA-NPs of NT-I } \\
\text { displayed lower brain } \\
\mathrm{T}_{\max } \text { and higher } \mathrm{C}_{\max } \text {. The } \\
\text { AUC } \mathrm{C}_{0-4 \mathrm{~h}} \text { values of } \mathrm{IV}-\mathrm{NP} \\
\text { and IN-NP were } 196 \% \\
\text { and } 160 \% \text {, respectively }\end{array}$ \\
\hline $\begin{array}{l}\text { Didanosin } \\
\mathrm{e}\end{array}$ & Brain & BNP & Chitosan and TPP & $\begin{array}{l}269-382 \mathrm{~nm}, 9.1 \text {, and } \\
47.3 \% \\
\text { loading efficacy and } \\
90.7 \text {, } 94.6 \% \\
\text { encapsulation } \\
\text { efficiency for } 10 \text { and } \\
50 \% \text { didanosine } \\
\text { theoretical loading, } \\
\text { respectively }\end{array}$ & $\begin{array}{l}\text { Rats/ IV and } \\
\text { IN solution }\end{array}$ & $\begin{array}{l}\text { The NPs had CNS/ } \\
\text { systemic distributions of } \\
1.9,2.5-3.3 \text {, and } 8.1-8.9 \\
\text { for the brain, olfactory } \\
\text { bulb and CSF, } \\
\text { respectively. The NPs } \\
\text { also showed } 70.9 \% \text { and } \\
38.9 \% \text { bioavailability } \\
\text { compared to the IV and } \\
\text { IN delivery of the drug } \\
\text { solution, respectively }\end{array}$ \\
\hline $\begin{array}{l}\text { Carboplati } \\
\mathrm{n}\end{array}$ & Brain & BNP & PCL and PVA & $\begin{array}{l}311.6 \mathrm{~nm} \text { and } \\
27.95 \% \text { entrapment } \\
\text { efficiency }\end{array}$ & $\begin{array}{l}\text { Rats/ In situ } \\
\text { nasal solution }\end{array}$ & $\begin{array}{l}\text { In situ nasal studies } \\
\text { demonstrated better nasal } \\
\text { absorption for carboplatin } \\
\text { from the NPs than the } \\
\text { drug solution }\end{array}$ \\
\hline Piperine & Brain & BNP & $\begin{array}{l}\text { Chitosan, TPP, and } \\
\text { Poloxamer } 188\end{array}$ & $\begin{array}{l}248.5 \mathrm{~nm} \text { and } 81.7 \% \\
\text { encapsulation } \\
\text { efficiency }\end{array}$ & $\begin{array}{l}\text { Rats/ IP } \\
\text { donepezil } \\
\text { pure drug and } \\
\text { blank NPs }\end{array}$ & $\begin{array}{l}\text { Significant cognitive } \\
\text { function improvement as } \\
\text { with donepezil with the } \\
\text { antioxidant and acetyl } \\
\text { choline esterase inhibitor }\end{array}$ \\
\hline bFGF & Brain & BNP & $\begin{array}{l}\text { STL, PEG, and } \\
\text { PLGA }\end{array}$ & $\begin{array}{l}118.7 \mathrm{~nm}, \quad 69.21 \% \\
\text { encapsulation and } \\
0.0462 \% \text { loading } \\
\text { efficiency }\end{array}$ & $\begin{array}{l}\text { Rats/ IV and } \\
\text { IN- bFGF }\end{array}$ & $\begin{array}{l}\text { The conjugated NPs } \\
\text { showed 1.79-5.17 and } \\
0.61-2.21 \text {-fold higher } \\
\text { brain concentrations than } \\
\text { the IV and IN delivery of } \\
\text { the unmodified NPs, } \\
\text { respectively. } \\
\text { modified solution also } \\
\text { demonstrated an }\end{array}$ \\
\hline
\end{tabular}




\begin{tabular}{|l|l|l|l|l|l|l|}
\hline & & & & & $\begin{array}{l}\text { improved cognitive } \\
\text { function }\end{array}$ \\
\hline Rasagiline & Brain & BNP & $\begin{array}{l}\text { Chitosan glutamate } \\
\text { and TPP }\end{array}$ & $\begin{array}{l}151.1 \quad \mathrm{~nm} \mathrm{and} \\
96.43 \% \\
\text { encapsulation } \\
\text { efficiency }\end{array}$ & $\begin{array}{l}\text { Mice/ IV and } \\
\text { IN rasagiline }\end{array}$ & $\begin{array}{l}\text { The rasagiline NP had 2.8 } \\
\text { and 1.7 higher brain } \\
\text { concentrations than the } \\
\text { IV and IN, respectively. } \\
\text { DTP was only 69.27\% }\end{array}$ \\
\hline
\end{tabular}

Abbreviations: NP, nanoparticle; bFGF, Basic fibroblast growth fact; IP, intraperitoneal; CSF, cerebrospinal fluid; STL, Solanum tuberosum lectin; NT-I, Neurotoxin-I; PCL, polycaprolactone, PLA; polylactic acid.

Biodegradable polymeric NPs are mainly based on chitosan and PLGA polymers. Their particle sizes are mostly in the range of 50-400 nm with high encapsulation efficiency. Moreover, modifications of the nanoparticles are common procedures and mainly applied by PEG and other materials, such as PLA and Poloxamer. These modifications are useful in achieving the delivery goals that have been determined.

\subsection{Topicalities of Intranasal Nanoparticles on the Pharmaceutical Market}

In the last decades, intranasal products for systemic delivery have been marketed successfully. Examples of such products are zolmatriptan (Zomig ${ }^{\circledR}$, Impax Laboratories Inc, USA) and sumatriptan (Imigran ${ }^{\circledR}$, GlaxoSmithKline, UK) for treatment of migraine, fentanyl (PecFent ${ }^{\circledR}$, Kyowa Kirin Services Ltd, Japan) for treatment of breakthrough pain in cancer and nicotine (Nicorette ${ }^{\circledast}$, McNeil AB, Sweden) for smoking cessation. Moreover, various nasal peptide products are currently on the market, such as calcitonin (Miacalcin, Novartis ${ }^{\circledR}$, USA) desmopressin (Desmospray ${ }^{\circledR}$, Ferring, UK), buserelin (Suprecur ${ }^{\circledR}$, SanofiAventis, UK) and nafarelin (Synarel ${ }^{\circledR}$, Pfizer Service, Belgium) oxytocin. On the other hand, an influenza virus vaccine has been introduced (Flumist ${ }^{\circledR}$, Medimmune, USA).

Despite the significant research efforts in the nanoparticles field, there is still no FDA approved nanoparticle-based product for intranasal delivery. Nanoparticulate systems for nasal delivery represent a relatively new approach. Despite the unavailable data from company pipelines about the clinical trial and development of these products, BlueWillow Biologics, Inc. showed some clinical trials for NEs as vaccines (Table 6). Research in this area should be continued at an even higher pace to investigate the possibilities of introducing nanotechnology as a delivery system via the nasal route for different targets.

Table 6. Examples of intranasal NEs for clinical consideration.

\begin{tabular}{|l|l|}
\hline \multicolumn{1}{|c|}{ Target } & \multicolumn{1}{c|}{ Status } \\
\hline \hline Seasonal influenza & Phase1 \\
\hline Pandemic influenza & Preclinical \\
\hline RSV & Preclinical \\
\hline Anthrax & Preclinical \\
\hline Pertussis & Preclinical \\
\hline HSV-2 & Preclinical \\
\hline Chlamydia & Preclinical \\
\hline Abbreviation: RSV, respiratory syncytial virus \\
\hline
\end{tabular}

\section{REGULATORY ASPECTS AND PATIENT EXPECTATIONS OF NASAL DELIVERY}

\subsection{Regulatory Aspects and QbD Implementation in Nasal Dosage Form Developments}

Prior to the development of intranasal formulations (similarly to other administration routes as well), the objectives, materials, methods, delivery systems, and expected outcomes should be identified clearly to end up with a product that can compromise between patients' demands and industrial expectation alongside with the regulatory guidelines of the FDA or EMA [237-239].

In 2005, the FDA enforced the submission of QbD with new drug application requests. The QbD approach provides a holistic view that can help in understanding and controlling the variables from the material selection to the scale up and commercialization of a medicinal product. Such designs offer the rewards of transferring the chemistry manufacturing control 
(CMC) of the new abbreviated drug into the pharmaceutical quality assessment, thus saving the time of development and submission, saving the time of regulatory authorities' approval, and defining the probability of out of specification and out of tolerance [240].

To implement QbD methodology, the quality target product profile (QTPP) must be defined initially. QTPP describes the profile of the drug delivery that is aimed to be reached; this will give the framework for the further adjustments during the development process. QbD-based development, later on, identifies the relations of the critical quality of attributes (CQAs), critical material attributes (CMA), and critical process parameters (CPP) with the product properties and control strategy according to ICH guidelines Q8, Q9, and Q10 to assess the product quality by referring to its efficacy and safety. For QbD, it is essential to apply a risk assessment and evaluation of the effects of the variables on production or the effects of the materials on safety and stability, thus it can help in the determination of the CQA and CMA, which highly affect the quality of the final product.

The application of $\mathrm{QbD}$ for intranasal nanoparticles has been introduced by Pallagi et al [241]. This study pointed out the importance of the risk assessment-based QbD on the early stage production of intranasal meloxicam nanosuspension by cogrinding with PVP-C30 stabilizer. The application of QbD provided an indication about the effects of parameters on the product quality, thus the researchers prioritized the study for the parameters of the greatest influence. Accordingly, the investigations revealed the importance of CPP (grinding time, rotation speed and meloxicam: PVP-C30 ratio) on CQA, particularly, particle size and dissolution rate. The optimization of $2 \mathrm{~h}$ grinding time, $400 \mathrm{rpm}$ rotation speed and 1:1 meloxicam: PVP-C30 was able to produce a nanosized product with $140 \mathrm{~nm}$ particle size and showed approximately $100 \%$ dissolution rate in the first $15 \mathrm{~min}$. The nanosized product was formulated into nasal hydrogel with sodium hyaluronate and it showed $\mathrm{C}_{\max }$ at $5 \mathrm{~min}$. Shah et al also applied the $\mathrm{QbD}$ approach for optimization rivastigmine SLN using homogenization and ultrasonication method. In this study, the authors set low particle size, low particle size distribution and high entrapment efficiency as CQAs. The effects of independent variables (drug: lipid ratio, surfactant concentration and homogenization time) on the previously determined CQAs were evaluated and a space design was built to determine the optimized formulation. The optimized formulation showed 82.5 particle size, 0.132 polydispersity index and $66.8 \%$ entrapment efficiency, also it showed 65.9\% ex vivo diffusion compared to $32.8 \%$ for the drug's solution. In another study, Shah et al reported the use of QbD and risk assessment and optimization of venlafaxine-loaded nanostructured lipid carrier. QbD was built and the CQAs were identified. From the design space, the optimized formulation was characterized by a particle size of $77 \mathrm{~nm}$, a particle size distribution of 0.234 and $81.3 \%$ entrapment efficiency. Moreover, it displayed a higher diffusion rate of $14.2 \mathrm{mg} / \mathrm{cm}^{2} / \mathrm{h}$ through nasal mucosa in comparison to $9.62 \mathrm{mg} / \mathrm{cm}^{2} / \mathrm{h}$ for the solution [188,242].

In accordance with intranasal literature, QbDs have been applied mainly to the formulations rather than the final product. Chudiwal et al reported the development of budesonide suspension nasal spray with QbD as a case study. In this study, the delivery device variables were recognized alongside the material and process variables [243].

Nanoparticles can be formulated into different dosage forms, such as liquids, gels, sprays, aerosols, and powders. The selection of the dosage forms depends on the drug type and formulation properties, the required effects and the targeted patient population. All traditional and new olfactory region targeted technologies, such as bidirectional (Optinose) ${ }^{\circledR}$, Controlled Particle Dispersion (CPD) ${ }^{\circledR}$ (Kurve), and Pressurized Olfactory Device (POD) can widen and specify the intranasal delivery for efficient outcomes [244,245].

Paying attention to the delivery system to meet the challenges of proper deposition and nasal cavity geometrical barriers is highly required. All technological parameters such as plume geometry and applied force directly affect the deposition of drugs; whereas, particle size has massive effects on the deposition as large particles tend to deposit in the anterior part without deep penetration.

The used delivery system must meet the FDA and EMA guidance requirements for nasal formulations, especially related to reproducibility and dose uniformity, besides the efficiency for delivering the formulation into the suitable regions. Such guidance offers great management for the quality aspects of nasal products and clarifies the requirements for regulations and the industry [237,246]. 
Fig. (2) represents the Ishikawa diagram. It shows the most important CPP and CMP, and the factors affecting drug products; whereas Fig. (3) shows the general flow chart for designing intranasal formulations. One can conclude from the complexity of the job (nanotechnology-based intranasal formulation), as illustrated in the figures, that a careful selection of the composition and the preparation method should be performed together with an initial risk assessment in order to directly get a product with the required quality parameters.

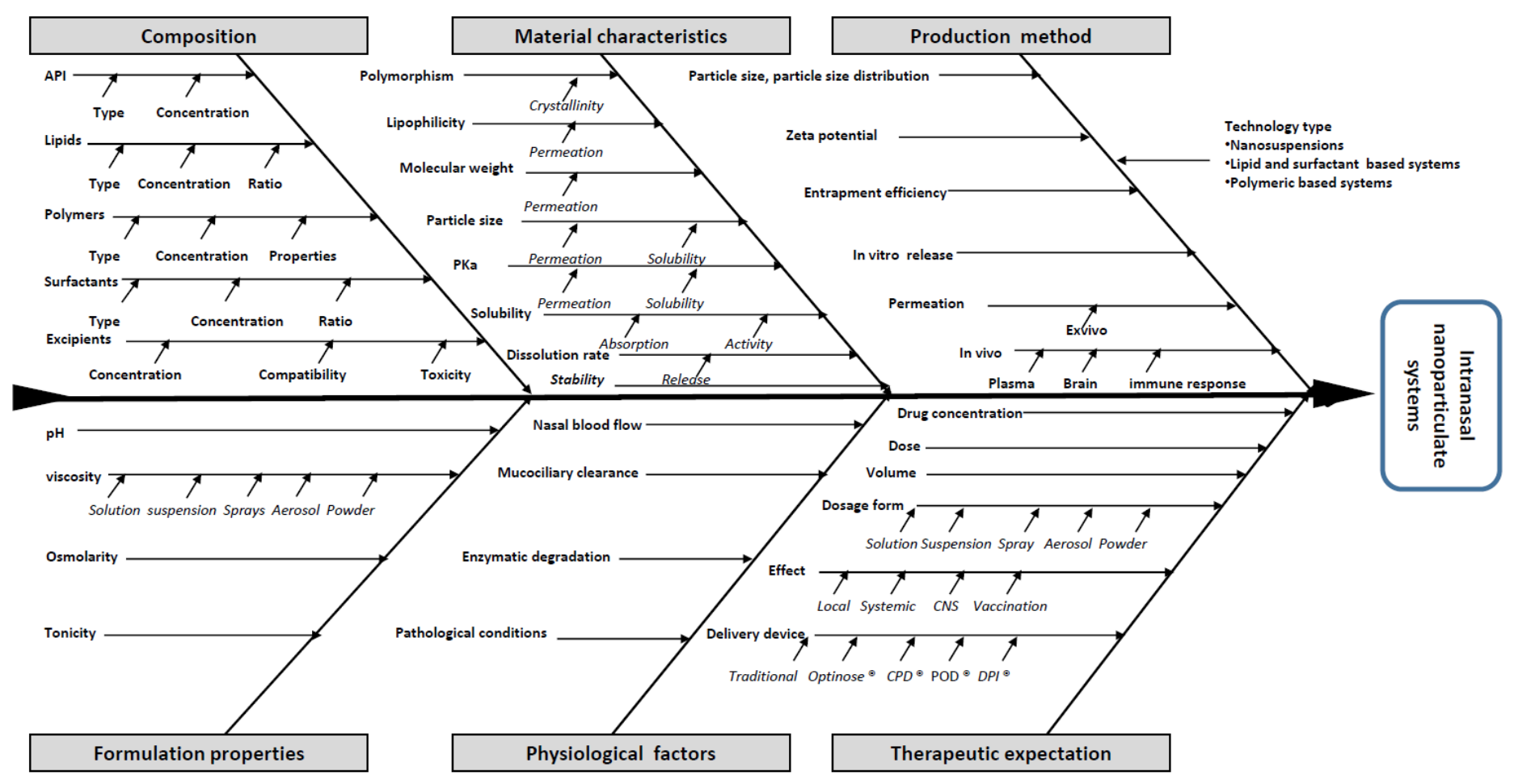

Fig. (2). Ishikawa diagram illustrating the parameters influencing the quality of an intranasal nanoparticulate system. 


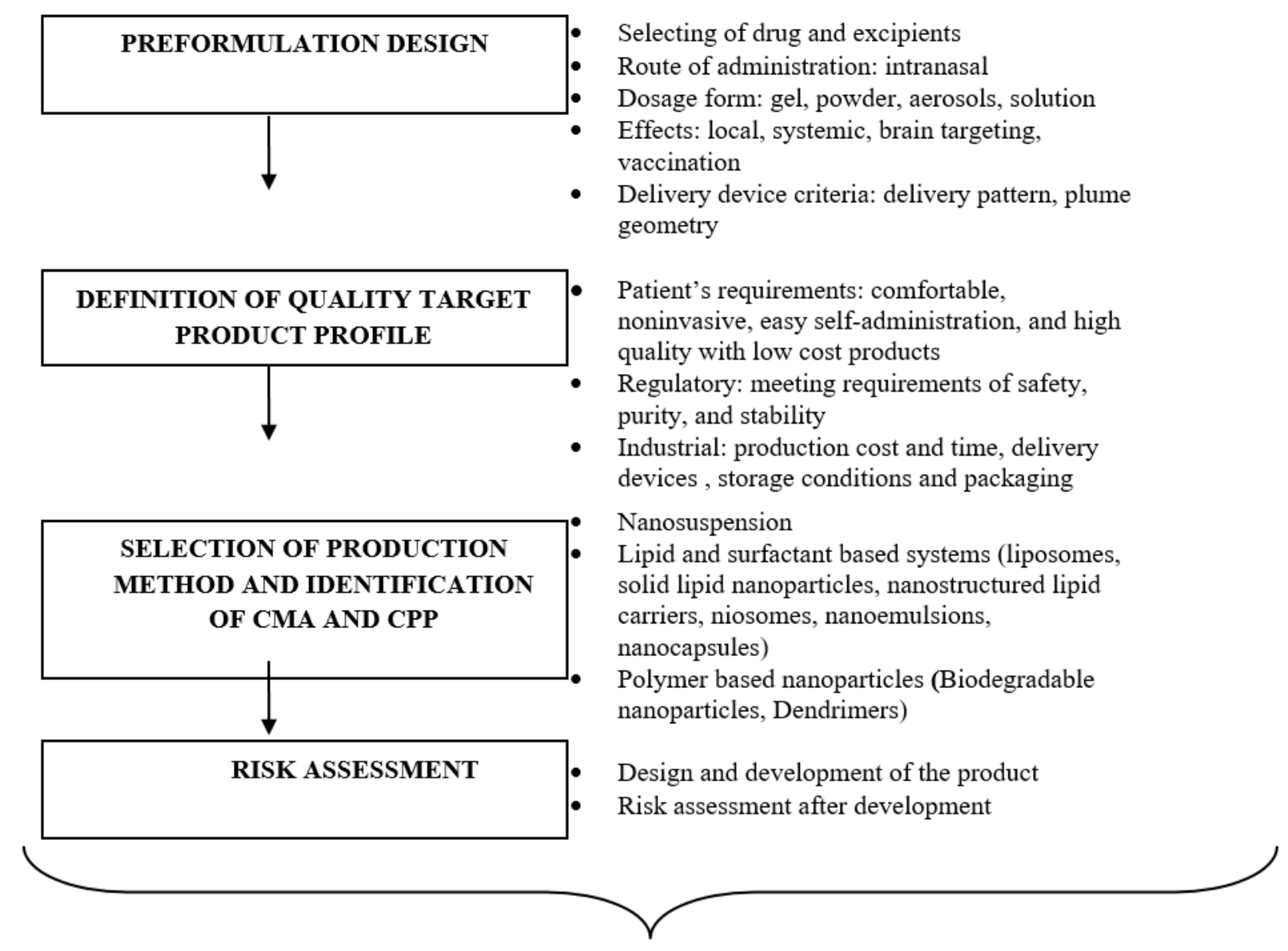

IDEAL INTRANASAL PRODUCT

Fig. (3). General method development strategy for intranasal nanoparticulates.

\subsection{Evaluation of Patients' Expectations of Intranasal Delivery}

Patients -as users of the medicinal products- have an increasing role in therapeutic success. Identifying what is expected or is critical for patients and reflecting these aspects during research and development is the first step to achieve patient acceptance and the required therapeutic outcome. This field has been ignored for many years, but as the effects of customers' preferences increase, it should be considered more as part of $R \& D$ thinking [247-249].

Patient requirements have extended the need for safe and efficient drug delivery to other concerns such as the comfort of both formulation and applicator device in the nasal cavity, the ease of application, confidence in the delivered amount, and a warning about the remaining dose (dose counting). All these factors can enhance patients' satisfaction and, therefore, their adherence [250,251]. In order to improve efficiency and productivity, manufacturers must understand the best tools, methods, and analysis. They have to define their goals on the basis of the patients' voices before proceeding into the production stage. Integrating the voice of the customer can help to assess the patients' convenience for their product and induce manufacturers to develop patient-friendly products. These considerations have not been kept in the theoretical framework or companies, but have transferred to the regulatory agencies that seriously consider patients' preferences and their assessments of using formulations and delivery devices [252].

\section{EXPERT OPINION}


The successful delivery of intranasal nanoformulations depends on many mutually dependent parameters: the selection of the nanotechnology method that can provide accepted encapsulation capacity and protection, the active pharmaceutical agent, the nanoparticulate system and the formulation properties, and the proper delivery system for the intended purposes. It is not an easy task to compromise between all aspects. Whilst various successful nanotechnology-based formulations have reached the market, intranasal products are still not available. Based on the previous literature and market research works, most marketed nasal products are available as nasal sprays and aerosols for local delivery, whilst the number of systemic and brain targeting products is lower and only one nasal vaccine is available.

The utilization of nanotechnology in intranasal delivery has shown promising results. The majority of the studies has focused on the efficiency of the delivery and how to modify the system to achieve acceptable outcomes, whilst the potential toxicity of these systems has not been adequately revealed. Lipid-based systems represent a high percentage of the studies. On the other hand, polymeric nanoparticles have focused mainly on chitosan, PLGA, and their modifications. Although the marketed products and patents for nanotechnology-based products are low, nanoemulsion adjuvant vaccines are under different clinical trials.

Nanoparticles/ nanocrystals have shown effective systemic, brain targeting, and vaccine delivery. However, it is not yet fully figured out if nanoparticles/ nanocrystals enhance delivery due to their design properties or due to their effects on residence time enhancement or/ and protection of the encapsulated agents against enzymatic degradation and the pg-efflux system.

The proper selection of the best system should not be separated from the final goal of providing a product combined for efficiency, safety, stability, and patient acceptance for acute and chronic use. Due to complexity, the implementation of QbD can offer a tool for early-stage assessment for constituents, methods, and delivery system selection in addition to the possibility of risk assessment before drug development. It is highly recommended to be adopted.

\section{CONCLUSION AND PROSPECTIVE FUTURE}

Intranasal delivery has shown the possibility of being a simple and direct method that can replace many traditional routes. Local delivery offers higher efficiency and lower side effects, systemic targeting can improve the bioavailability of many agents and nasal vaccination produces rapid mucosal and systemic immunity that has not been achieved by the parenteral route. Nanoparticles showed the advantages of drug protection, enhancement of contact time, enhancement of drug solubility, ability of being easily functionalized and using of GRAS excipient. Therefore, they have the potential to overcome the traditional limitation of the nasal delivery. The suitability of intranasal nanoparticles for brain targeting and bypassing the blood brain barrier has demonstrated a way for treatment of unresolved CNS conditions and opened a new scope for treatment of aggressive brain tumors either by drugs or vaccine delivery. The intranasal administration of nanoparticles for a systemic effect showed effective results with regard to bioavailability, plasma maximum concentration, and time to reach the maximum concentration. Moreover, different studies on nanoparticle-based vaccines displayed the ability of these systems to elicit mucosal and systemic immune responses with adjuvant activity.

The successful formulations can map the future of intranasal delivery. However, there are still many challenges to face. Increasing knowledge of nanotechnology is the first step towards successful delivery. The two-branch approach of utilizing nanoparticles coupled with intranasal delivery can provide the opportunities for efficient and convenient drug (vaccine) delivery. Accordingly, the future decades will most likely witness the production of intranasal formulations that overcome the current limitations.

\section{Declaration of interest}

The authors state no conflict of interest and have received no payment for the preparation of this manuscript. 


\section{REFERENCES}

[1] Kipp, J. E. The Role of Solid Nanoparticle Technology in the Parenteral Delivery of Poorly Water-Soluble Drugs. Int. J. Pharm. 2004, 284 (1-2), 109-122

[2] Merisko-Liversidge, E. M.; Liversidge, G. G. Drug Nanoparticles: Formulating Poorly Water-Soluble Compounds. Toxicol. Pathol. 2008, 36 (1), 43-48

[3] Prabhakar, U.; Maeda, H.; K. Jain, R.; Sevick-Muraca, E. M.; Zamboni, W.; Farokhzad, O. C.; Barry, S. T.; Gabizon, A.; Grodzinski, P.; Blakey, D. C. Challenges and Key Considerations of the Enhanced Permeability and Retention Effect for Nanomedicine Drug Delivery in Oncology. Cancer Res. 2013, 73 (8), 2412-2417

[4] Kadam, R. S.; Bourne, D. W. A.; Kompella, U. B. Nano-Advantage in Enhanced Drug Delivery with Biodegradable Nanoparticles: Contribution of Reduced Clearance. Drug Metab. Dispos. 2012, 40 (7), 1380-1388

[5] Kawasaki, E. S.; Player, A. Nanotechnology, Nanomedicine, and the Development of New, Effective Therapies for Cancer. Nanomedicine Nanotechnology, Biol. Med. 2005, 1 (2), 101-109

[6] Li, B.; Li, Q.; Mo, J.; Dai, H. Drug-Loaded Polymeric Nanoparticles for Cancer Stem Cell Targeting. Front. Pharmacol. 2017, 8 (February), 51

[7] Trivedi, R.; Kompella, U. B. Nanomicellar Formulations for Sustained Drug Delivery: Strategies and Underlying Principles. Nanomedicine (Lond). 2010, 5 (3), 485-505

[8] Zhang, L.; Gu, F. X.; Chan, J. M.; Wang, A. Z.; Langer, R. S.; Farokhzad, O. C. Nanoparticles in Medicine: Therapeutic Applications and Developments. Educ. Policy Anal. Arch. 2000, 8 (5), 761-769

[9] Gaumet, M.; Vargas, A.; Gurny, R.; Delie, F. Nanoparticles for Drug Delivery: The Need for Precision in Reporting Particle Size Parameters. Eur. J. Pharm. Biopharm. 2008, 69 (1), 1-9

[10] Gaspar, R. S.; Florindo, H. F.; Silva, L. C.; Videira, M. A.; Corvo, M. L.; Martins, B. F.; Silva-Lima, B. Regulatory Aspects of Oncologicals: Nanosystems Main Challenges. In Alonso M, Garcia-Fuentes M, Editors. Nano-Oncologicals New Targeting and Delivery Approaches; Springer, Cham. 2014, pp 425-452

[11] Cai, Z.; Wang, Y.; Zhu, L.-J.; Liu, Z.-Q. Nanocarriers: A General Strategy for Enhancement of Oral Bioavailability of Poorly Absorbed or Pre-Systemically Metabolized Drugs. Curr. Drug Metab. 2010, 11 (2), 197-207

[12] Doane, T. L.; Burda, C. The Unique Role of Nanoparticles in Nanomedicine: Imaging, Drug Delivery and Therapy. Chem. Soc. Rev. 2012, 41 (7), 2885-2911

[13] Kocbek, P.; Baumgartner, S.; Kristl, J. Preparation and Evaluation of Nanosuspensions for Enhancing the Dissolution of Poorly Soluble Drugs. Int. J. Pharm. 2006, 312 (1-2), 179-186

[14] Nanotechnology - FDA's Approach to Regulation of Nanotechnology Products. Available from: www.fda.gov (Accessed Jul 24,2017)

[15] European Medicines Agency - Human regulatory - Human medicines: regulatory information. https://www.ema.europa.eu/en/human-medicines-regulatory-information. (Accessed Jul 24,2017)

[16] Guidance for Industry Nasal Spray and Inhalation Solution, Suspension and Spray Drug Products — Chemistry, Manufacturing and Controls Documentation. 2002, 301-827. Https://www.fda.gov/media/70857/download. (Accessed Jul 24,2017)

[17] Guidance for Industry Bioavailability and Bioequivalence Studies for Nasal Aerosols and Nasal Sprays for Local Action. Local Action. 2003, 20857 (April), 37. Https://www.fda.gov/regulatory-information/search-fda-guidancedocuments/bioavailability-and-bioequivalence-studies-nasal-aerosols-and-nasal-sprays-local-action. (Accessed Jul 24,2017).

[18] EMEA/CHMP, 2009, ICH Topic Q 8 (R2) Pharmaceutical Development, Step 5: Note for Guidance on Pharmaceutical Development, Http://Www.Ema.Europa.Eu/Docs/En_GB/Document_library/Scientific_guideline/2010/01/W C500059258.Pdf ( Accessed Jul 24,2017).

[19] EMA/CHMP, 2014, ICH Guideline Q9 on Quality Risk Management, Http://Www.Ema.Europa.Eu/Docs/En_GB/Document_library/Scientific_guideline/2009/09/W C500002873.Pdf, Accessed: 3/11/2014 (Accessed Jul 24,2017).

[20] EMA/CHMP, 2014, ICH Guideline Q10 on Pharmaceutical Quality System, Http://Www.Ema.Europa.Eu/Docs/En_GB/Document_library/Scientific_guideline/2009/09/W C500002871.Pdf (Accessed Jul 24,2017).

[21] Graff, C. L.; Pollack, G. M. Nasal Drug Administration: Potential for Targeted Central Nervous System Delivery. $J$. Pharm. Sci. 2005, 94 (6), 1187-1195

[22] Kapoor, M.; Cloyd, J. C.; Siegel, R. A. A Review of Intranasal Formulations for the Treatment of Seizure Emergencies. J. Control. Release. 2016, 237, 147-159

[23] Arora, P.; Sharma, S.; Garg, S. Permeability Issues in Nasal Drug Delivery. Drug Discov. Today. 2002, 7 (18), $967-$ 975

[24] Chapman, C. D.; Frey, W. H.; Craft, S.; Danielyan, L.; Hallschmid, M.; Schiöth, H. B.; Benedict, C. Intranasal 
Treatment of Central Nervous System Dysfunction in Humans. Pharm. Res. 2013, 30 (10), 2475-2484 Including Centrifugal Fibers to the Olfactory Bulb. J. Comp. Neurol. 1983, 216 (3), 264-291

[26] Illum, L. Nasal Clearance in Health and Disease. J. Aerosol Med. 2006, 19 (1), 92-99

[27] Mygind, N.; Dahl, R. Anatomy, Physiology and Function of the Nasal Cavities in Health and Disease. Adv. Drug Deliv. Rev. 1998, 29 (1-2), 3-12

[28] Charlton, S.; Jones, N. S.; Davis, S. S.; Illum, L. Distribution and Clearance of Bioadhesive Formulations from the Olfactory Region in Man: Effect of Polymer Type and Nasal Delivery Device. Eur. J. Pharm. Sci. 2007, 30 (3-4), 295 302

[29] Iwai, N.; Zhou, Z.; Roop, D. R.; Behringer, R. R. Horizontal Basal Cells Are Multipotent Progenitors in Normal and Injured Adult Olfactory Epithelium. Stem Cells. 2008, 26 (5), 1298-1306

[30] Lochhead, J. J.; Thorne, R. G. Intranasal Delivery of Biologics to the Central Nervous System. Adv. Drug Deliv. Rev. 2012, 64 (7), 614-628

[31] Kublik, H.; Vidgren, M. . Nasal Delivery Systems and Their Effect on Deposition and Absorption. Adv. Drug Deliv. Rev. 1998, 29 (1), 157-177

[32] Johnson, N. J.; Hanson, L. R.; Frey, W. H. Trigeminal Pathways Deliver a Low Molecular Weight Drug from the Nose to the Brain and Orofacial Structures. Mol Pharm.2010, 7 (3), 884-893

[33] Menzel, C.; Jelkmann, M.; Laffleur, F.; Bernkop-Schnürch, A. Nasal Drug Delivery: Design of a Novel Mucoadhesive and in Situ Gelling Polymer. Int. J. Pharm. 2017, 517 (1-2), 196-202

[34] Kammona, O.; Kiparissides, C. Recent Advances in Nanocarrier-Based Mucosal Delivery of Biomolecules. J. Control. Release. 2012, 161 (3), 781-794

[35] Badhan, R. K. S.; Kaur, M.; Lungare, S.; Obuobi, S. Improving Brain Drug Targeting through Exploitation of the Noseto- Brain Route: A Physiological and Pharmacokinetic Perspective. Curr. Drug Deliv. 2014, 11 (4), 458-471

[36] Costantino, H. R.; Illum, L.; Brandt, G.; Johnson, P. H.; Quay, S. C. Intranasal Delivery: Physicochemical and Therapeutic Aspects. Int. J. Pharm. 2007, 337 (1-2), 1-24

[37] Bitter, C.; Suter-Zimmermann, K.; Surber, C. Nasal Drug Delivery in Humans. Top. Appl. Mucosa. 2011, 40 (c), 20-35

[38] Grassin-Delyle, S.; Buenestado, A.; Naline, E.; Faisy, C.; Blouquit-Laye, S.; Couderc, L. J.; Le Guen, M.; Fischler, M.; Devillier, P. Intranasal Drug Delivery: An Efficient and Non-Invasive Route for Systemic Administration - Focus on Opioids. Pharmacol. Ther. 2012, 134 (3), 366-379

[39] Singh; A, Singh; A, Madiv, N. Nasal Cavity: A Promising Transmucosal Platform for Drug Delivery and Research Approaches from Nasal to Brain Targeting. J. Drug Deli very Ther. 2012, 2 (3), 22-33

[40] Gizurarson, S. The Effect of Cilia and the Mucociliary Clearance on Successful Drug Delivery. Biol. Pharm. Bull. 2015, $38(4), 497-506$

[41] Dale, O.; Hjortkjaer, R.; Kharasch, E. D. Nasal Administration of Opioids for Pain Management in Adults. Acta Anaesthesiol. Scand. 2002, 46 (7), 759-770

[42] Merkus, P.; Romeijn, S. G.; Verhoef, J. C.; Merkus, F. W.; Schouwenburg, P. F. Classification of Cilio-Inhibiting Effects of Nasal Drugs. Laryngoscope. 2001, 111 (4 Pt 1), 595-602

[43] Gizurarson, S. The Relevance of Nasal Physiology to the Design of Drug Absorption Studies. Adv. Drug Deliv. Rev. 1993, $11(3), 329-347$

[44] Djupesland, P. G. Nasal Drug Delivery Devices: Characteristics and Performance in a Clinical Perspective-a Review. Drug Deliv. Transl. Res. 2013, 3 (3), 137-144

[45] Stahl, E.; van Rompay, W.; Wang, E. C.; Thomson, D. M. Cost-Effectiveness Analysis of Budesonide Aqueous Nasal Spray and Fluticasone Propionate Nasal Spray in the Treatment of Perennial Allergic Rhinitis. Ann Allergy Asthma Immunol. 2000, 84 (4), 397-402

[46] Li, B. V; Jin, F.; Lee, S. L.; Bai, T.; Chowdhury, B.; Caramenico, H. T.; Conner, D. P. Bioequivalence for Locally Acting Nasal Spray and Nasal Aerosol Products: Standard Development and Generic Approval. AAPS J. 2013, 15 (3), 875-883

[47] Trangsrud, A. J.; Whitaker, A. L.; Small, R. E. Intranasal Corticosteroids for Allergic Rhinitis. Pharmacotherapy. 2002, 22 (11), 1458-1467

[48] Shah, S. R.; Nayak, A.; Ratner, P.; Roland, P.; Wall, G. M. Effects of Olopatadine Hydrochloride Nasal Spray 0 . $6 \%$ in the Treatment of Seasonal Allergic Rhinitis : A Phase III, Controlled Study in Adolescents and Adults. Clin. Ther. 2009, 31 (1), 99-107

[49] Türker, S.; Onur, E.; Ózer, Y. Nasal Route and Drug Delivery Systems. Pharm. World Sci. 2004, 26 (3), 137-142

[50] Vyas, T. K.; Shahiwala, A.; Marathe, S.; Misra, A. Intranasal Drug Delivery for Brain Targeting. Curr. Drug Deliv. 2005, 2 (2), 165-175

[51] Meredith, E.; Salameh, T. S.; Banks, W. A. Intranasal Delivery of Proteins and Peptides in the Treatment of Neurodegenerative Diseases. AAPS J. 2015, 17 (4), 780-787

[52] Jabbal-Gill, I. Nasal Vaccine Innovation. J. Drug Target. 2010, 18 (10), 771-786

[53] Thwala, L. N.; Préat, V.; Csaba, N. S. Emerging Delivery Platforms for Mucosal Administration of Biopharmaceuticals: A Critical Update on Nasal, Pulmonary and Oral Routes. 2016, 14 (1), 23-36 
[54] Gawel, M.; Aschoff, J.; May, A.; Charlesworth, B. R. Zolmitriptan 5 Mg Nasal Spray: Efficacy and Onset of Action in the Acute Treatment of Migraine - Results from Phase 1 of the REALIZE Study. Headache. 2005, 45 (1), 7-16

[55] Dodick, D.; Brandes, J.; Elkind, A.; Mathew, N.; Rodichok, L. Speed of Onset, Efficacy and Tolerability of Zolmitriptan Nasal Spray in the Acute Treatment of Migraine: A Randomised, Double-Blind, Placebo-Controlled Study. CNS Drugs. 2005, 19 (2), 125-136

[56] Munjal, S.; Gautam, A.; Offman, E.; Brand-Schieber, E.; Allenby, K.; Fisher, D. M. A Randomized Trial Comparing the Pharmacokinetics, Safety, and Tolerability of DFN-02, an Intranasal Sumatriptan Spray Containing a Permeation Enhancer, With Intranasal and Subcutaneous Sumatriptan in Healthy Adults. Headache. 2016, 56 (9), 1455-1465

[57] Winner, P.; Rothner, A. D.; Wooten, J. D.; Webster, C.; Ames, M. Sumatriptan Nasal Spray in Adolescent Migraineurs: A Randomized, Double-Blind, Placebo-Controlled, Acute Study. Headache. 2006, 46 (2), 212-222

[58] Abboud, T. K.; Zhu, J.; Longhitano, M.; Minehart, M.; Mantilla, M.; Chu, G.; Kimball, S.; Rodriguez, J.; Terrasi, J.; Gangolli, J.; et al. Efficacy and Safety of Butorphanol Nasal Spray for the Relief of Postepisiotomy Pain. Curr. Ther. Res. 1994, 55 (5), 500-509

[59] Nave, R.; Schmitt, H.; Popper, L. Faster Absorption and Higher Systemic Bioavailability of Intranasal Fentanyl Spray Compared to Oral Transmucosal Fentanyl Citrate in Healthy Subjects. Drug Deliv. 2013, 7544 (5), 216-223

[60] Nozaki, A.; Ando, T.; Akazawa, S.; Satoh, T.; Sagara, I.; Horie, I.; Imaizumi, M.; Usa, T.; Yanagisawa, R. T.; Kawakami, A. Quality of Life in the Patients with Central Diabetes Insipidus Assessed by Nagasaki Diabetes Insipidus Questionnaire. Endocrine. 2016, 51 (1), 140-147

[61] El-Nemr, A.; Bhide, M.; Khalifa, Y.; Al-Mizyen, E.; Gillott, C.; Lower, A. M.; Al-Shawaf, T.; Grudzinskas, J. G. Clinical Evaluation of Three Different Gonadotrophin-Releasing Hormone Analogues in an IVF Programme: A Prospective Study. Eur. J. Obstet. Gynecol. Reprod. Biol. 2002, 103 (2), 140-145

[62] Kapoor, M.; Winter, T.; Lis, L.; Georg, G. I.; Siegel, R. A. Rapid Delivery of Diazepam from Supersaturated Solutions Prepared Using Prodrug/Enzyme Mixtures: Toward Intranasal Treatment of Seizure Emergencies. AAPS J. 2014, 16 (3), 577-585

[63] Corrigan, M.; Wilson, S. S.; Hampton, J. Safety and Efficacy of Intranasally Administered Medications in the Emergency Department and Prehospital Settings. Am. J. Heal. Pharm. 2015, 72 (18), 1544-1554

[64] Afridi, S. K.; Giffin, N. J.; Kaube, H.; Goadsby, P. J. A Randomized Controlled Trial of Intranasal Ketamine in Migraine with Prolonged Aura. Neurology. 2013, 80 (7), 642-647

[65] Graudins, A.; Meek, R.; Egerton-Warburton, D.; Oakley, E.; Seith, R. The PICHFORK (Pain in Children Fentanyl or Ketamine) Trial: A Randomized Controlled Trial Comparing Intranasal Ketamine and Fentanyl for the Relief of Moderate to Severe Pain in Children with Limb Injuries. Ann. Emerg. Med. 2015, 65 (3), 248-254.e1

[66] Pavis, H.; Wilcock, A.; Edgecombe, J.; Carr, D.; Manderson, C.; Church, A.; Fisher, A. Pilot Study of Nasal MorphineChitosan for the Relief of Breakthrough Pain in Patients with Cancer. J. Pain Symptom Manage. 2002, 24 (6), 598-602

[67] Steenblik, J.; Goodman, M.; Davis, V.; Gee, C.; Hopkins, C. L.; Stephen, R.; Madsen, T. Intranasal Sufentanil for the Treatment of Acute Pain in a Winter Resort Clinic. Am. J. Emerg. Med. 2012, 30 (9), 1817-1821

[68] Pardridge, W. M. The Blood-Brain Barrier: Bottleneck in Brain Drug Development. NeuroRx. 2005, 2 (1), 3-14

[69] Howard, P.; Twycross, R.; Shuster, J.; Mihalyo, M.; Wilcock, A. Antidepressant Drugs. J. Pain Symptom Manage. 2012, 44 (5), 763-783

[70] Antinori, A.; Cingolani, A.; Giancola, M. L.; Forbici, F.; De Luca, A.; Perno, C. F. Clinical Implications of HIV-1 Drug Resistance in the Neurological Compartment. Scand. J. Infect. Dis. Suppl. 2003, 106, 41-44

[71] Zaman, M.; Chandrudu, S.; Toth, I. Strategies for Intranasal Delivery of Vaccines. Drug Deliv. Transl. Res. 2013, 3 (1), 100-109

[72] Fujimura, Y.; Takeda, M.; Ikai, H.; Haruma, K.; Akisada, T.; Harada, T.; Sakai, T.; Ohuchi, M. The Role of M Cells of Human Nasopharyngeal Lymphoid Tissue in Influenza Virus Sampling. Virchows Arch. 2004, 444 (1), 36-42

[73] Davis, S. S. Nasal Vaccines. Adv. Drug Deliv. Rev. 2001, 51 (1-3), 21-42

[74] Lawson, L. B.; Norton, E. B.; Clements, J. D. Defending the Mucosa: Adjuvant and Carrier Formulations for Mucosal Immunity. Curr. Opin. Immunol. 2011, 23 (3), 414-420

[75] Sharma, S.; Mukkur, T. K. S.; Benson, H. A. E.; Chen, Y. Pharmaceutical Aspects of Intranasal Delivery of Vaccines Using Particulate Systems. Journal of Pharmaceutical Sciences. 2009, pp 812-843

[76] Wang, J.; Liu, Y.; Jiao, F.; Lao, F.; Li, W.; Gu, Y.; Li, Y.; Ge, C.; Zhou, G.; Li, B.; et al. Time-Dependent Translocation and Potential Impairment on Central Nervous System by Intranasally Instilled TiO2 Nanoparticles. Toxicology. 2008, 254 (1-2), 82-90

[77] Ong, W.-Y.; Shalini, S.-M.; Costantino, L. Nose-to-Brain Drug Delivery by Nanoparticles in the Treatment of Neurological Disorders. Curr. Med. Chem. 2014, 21 (37), 4247-4256

[78] De Jong, W. H.; Borm, P. J. Drug Delivery and Nanoparticles: Applications and Hazards. Int. J. Nanomedicine. 2008, 3 (2), 133-149

[79] Chen, H.; Khemtong, C.; Yang, X.; Chang, X.; Gao, J. Nanonization Strategies for Poorly Water-Soluble Drugs. Drug 
Discov. Today. 2011, 16 (7-8), 354-360

[80] Milhem, O. M.; Myles, C.; McKeown, N. B.; Attwood, D.; D’Emanuele, A. Polyamidoamine Starburst ${ }^{\circledR}$ Dendrimers as Solubility Enhancers. Int. J. Pharm. 2000, 197 (1-2), 239-241

[81] Devarakonda, B.; Hill, R. A.; De Villiers, M. M. The Effect of PAMAM Dendrimer Generation Size and Surface Functional Group on the Aqueous Solubility of Nifedipine. Int. J. Pharm. 2004, 284 (1-2), 133-140

[82] Pistolis, G.; Malliaris, A.; Tsiourvas, D.; Paleos, C. M. Poly ( Propyleneimine ) Dendrimers as PH-Sensitive Controlled-Release Systems. 1999, No. 5, 1440-1444

[83] Shrestha, H.; Bala, R.; Arora, S. Lipid-Based Drug Delivery Systems. J. Pharm. 2014, 1-10

[84] Cui, F.; Qian, F.; Yin, C. Preparation and Characterization of Mucoadhesive Polymer-Coated Nanoparticles. Int. J. Pharm. 2006, 316 (1-2), 154-161

[85] Issa, M. M.; Köping-Höggård, M.; Artursson, P. Chitosan and the Mucosal Delivery of Biotechnology Drugs. Drug Discov. Today Technol. 2005, 2 (1), 1-6

[86] Pawar, D.; Goyal, A. K.; Mangal, S.; Mishra, N.; Vaidya, B.; Tiwari, S.; Jain, A. K.; Vyas, S. P. Evaluation of Mucoadhesive PLGA Microparticles for Nasal Immunization. AAPS J. 2010, 12 (2), 130-137

[87] Gao, X.; Tao, W.; Lu, W.; Zhang, Q.; Zhang, Y.; Jiang, X.; Fu, S. Lectin-Conjugated PEG-PLA Nanoparticles: Preparation and Brain Delivery after Intranasal Administration. Biomaterials. 2006, 27 (18), 3482-3490

[88] Bernocchi, B.; Carpentier, R.; Lantier, I.; Ducournau, C.; Dimier-Poisson, I.; Betbeder, D. Mechanisms Allowing Protein Delivery in Nasal Mucosa Using NPL Nanoparticles. J. Control. Release. 2016, 232, 42-50

[89] Kato, Y.; Hosokawa, T.; Hayakawa, E.; Ito, K. Influence of Liposomes on Tryptic Digestion of Insulin. Biol. Pharm. Bull. 1992, 16 (5), 457-461

[90] Shah, L.; Yadav, S.; Amiji, M. Nanotechnology for CNS Delivery of Bio-Therapeutic Agents. Drug Deliv. Transl. Res. 2013, 3 (4), 336-351

[91] Chavanpatil, M. D.; Khdair, A.; Gerard, B.; Bachmeier, C.; Miller, D. W.; Shekhar, M. P. V.; Panyam, J. SurfactantPolymer Nanoparticles Overcome P-Glycoprotein-Mediated Drug Efflux. Mol. Pharm. 2007, 4 (5), 730-738

[92] Rahisuddin; Sharma, P. K.; Garg, G.; Salim, M. Review on Nasal Drug Delivery System with Recent Advancemnt. Int. J. Pharm. Pharm. Sci. 2011, 3 (SUPPL. 2), 6-11

[93] Anantachaisilp, S.; Smith, S. M.; Treetong, A.; Pratontep, S.; Puttipipatkhachorn, S.; Ruktanonchai, U. R. Chemical and Structural Investigation of Lipid Nanoparticles: Drug-Lipid Interaction and Molecular Distribution.

Nanotechnology. 2010, 21 (12), 125102, (11pp)

[94] Shin, S.; Song, I.; Um, S. Role of Physicochemical Properties in Nanoparticle Toxicity. Nanomaterials. 2015, 5 (3), 1351-1365

[95] Lockman, P. R.; Koziara, J. M.; Mumper, R. J.; Allen, D. D. Nanoparticle Surface Charges Alter Blood-Brain Barrier Integrity and Permeability. J. Drug Target. 2004, 12 (9-10), 635-641

[96] Alpar, H. O.; Somavarapu, S.; Atuah, K. N.; Bramwell, V. W. Biodegradable Mucoadhesive Particulates for Nasal and Pulmonary Antigen and DNA Delivery. Advanced Drug Delivery Reviews. 2005, pp 411-430

[97] Sonvico, F.; Clementino, A.; Buttini, F.; Colombo, G.; Pescina, S.; Guterres, S. S.; Pohlmann, A. R.; Nicoli, S. SurfaceModified Nanocarriers for Nose-to-Brain Delivery: From Bioadhesion to Targeting. Pharmaceutics. 2018, 10 (1), 1-34

[98] Brooking, J.; Davis, S. S.; Illum, L. Transport of Nanoparticles across the Rat Nasal Mucosa. J. Drug Target. 2001, 9 (4), 267-279

[99] Kawaguchi, H.; Koiwai, N.; Ohtsuka, Y.; Miyamoto, M.; Sasakawa, S. Phagocytosis of Latex Particles by Leucocytes. I. Dependence of Phagocytosis on the Size and Surface Potential of Particles. Biomaterials. 1986, 7 (1), 61-66

[100] Gartziandia, O.; Egusquiaguirre, S. P.; Bianco, J.; Pedraz, J. L.; Igartua, M.; Hernandez, R. M.; Préat, V.; Beloqui, A. Nanoparticle Transport across in Vitro Olfactory Cell Monolayers. Int. J. Pharm. 2016, 499 (1-2), 81-89

[101] Mistry, A.; Stolnik, S.; Illum, L. Nose-to-Brain Delivery: Investigation of the Transport of Nanoparticles with Different Surface Characteristics and Sizes in Excised Porcine Olfactory Epithelium. Mol. Pharm. 2015, 12 (8), 2755-2766

[102] Ahmad, E.; Feng, Y.; Qi, J.; Fan, W.; Ma, Y.; He, H.; Xia, F.; Dong, X.; Zhao, W.; Lu, Y.; Wu, W. Evidence of Noseto-Brain Delivery of Nanoemulsions: Cargoes but Not Vehicles. Nanoscale 2017, 9 (3), 1174-1183

[103] Gratton, S. E. A.; Ropp, P. A.; Pohlhaus, P. D.; Luft, J. C.; Madden, V. J.; Napier, M. E.; DeSimone, J. M. The Effect of Particle Design on Cellular Internalization Pathways. Proc. Natl. Acad. Sci. 2008, 105 (33), 11613-11618

[104] Chithrani, B. D.; Ghazani, A. A.; Chan, W. C. W. Determining the Size and Shape Dependence of Gold Nanoparticle Uptake into Mammalian Cells. Nano Lett. 2006, 6 (4), 662-668

[105] Shi, W.; Wang, J.; Fan, X.; Gao, H. Size and Shape Effects on Diffusion and Absorption of Colloidal Particles near a Partially Absorbing Sphere: Implications for Uptake of Nanoparticles in Animal Cells. Phys. Rev. E. 2008, 78 (6), 061914

[106] Qiu, Y.; Liu, Y.; Wang, L.; Xu, L.; Bai, R.; Ji, Y.; Wu, X.; Zhao, Y.; Li, Y.; Chen, C. Surface Chemistry and Aspect Ratio Mediated Cellular Uptake of Au Nanorods. Biomaterials. 2010, 31 (30), 7606-7619

[107] Chithrani, B. D.; Chan, W. C. W. Elucidating the Mechanism of Cellular Uptake and Removal of Protein-Coated Gold Nanoparticles of Different Sizes and Shapes. Nano Lett. 2007, 7 (6), 1542-1550

[108] Oh, N.; Park, J. H. Endocytosis and Exocytosis of Nanoparticles in Mammalian Cells. Int. J. Nanomedicine. 2014, 9 (SUPPL.1), 51-63 
[109] Gan, Q.; Wang, T. Chitosan Nanoparticle as Protein Delivery Carrier-Systematic Examination of Fabrication Conditions for Efficient Loading and Release. Colloids Surfaces B Biointerfaces. 2007, 59 (1), 24-34

[110] Lai, S. K.; Wang, Y. Y.; Hanes, J. Mucus-Penetrating Nanoparticles for Drug and Gene Delivery to Mucosal Tissues. Adv. Drug Deliv. Rev. 2009, 61 (2), 158-171

[111] Liu, M.; Zhang, J.; Shan, W.; Huang, Y. Developments of Mucus Penetrating Nanoparticles. Asian J. Pharm. Sci. 2014, 10 (4), 275-282

[112] Vila, A.; Sánchez, A.; Évora, C.; Soriano, I.; Vila Jato, J. L; Alonso, M. J. PEG-PLA Nanoparticles as Carriers For Nasal Vaccine Delivery. J. Aerosol Med. 2004, 17 (2), 174-185

[113] Narayan, R.; Singh, M.; Ranjan, O.; Nayak, Y.; Garg, S.; Shavi, G. V.; Nayak, U. Y. Development of Risperidone Liposomes for Brain Targeting through Intranasal Route. Life Sci. 2016, 163, 38-45

[114] Müller, R. H.; Gohla, S.; Keck, C. M. State of the Art of Nanocrystals - Special Features, Production, Nanotoxicology Aspects and Intracellular Delivery. Eur. J. Pharm. Biopharm. 2011, 78 (1), 1-9

[115] Kürti, L.; Gáspár, R.; Márki, Á.; Kápolna, E.; Bocsik, A.; Veszelka, S.; Bartos, C.; Ambrus, R.; Vastag, M.; Deli, M.A.; Szabó-Révész, P. In Vitro and in Vivo Characterization of Meloxicam Nanoparticles Designed for Nasal Administration. Eur. J. Pharm. Sci. 2013, 50 (1), 86-92

[116] Hao, J.; Zhao, J.; Zhang, S.; Tong, T.; Zhuang, Q.; Jin, K.; Chen, W.; Tang, H. Fabrication of an Ionic-Sensitive in Situ Gel Loaded with Resveratrol Nanosuspensions Intended for Direct Nose-to-Brain Delivery. Colloids Surfaces B Biointerfaces. 2016, 147, 376-386

[117] Saindane, N. S.; Pagar, K. P.; Vavia, P. R. Nanosuspension Based in Situ Gelling Nasal Spray of Carvedilol: Development, in Vitro and in Vivo Characterization. AAPS.PharmSciTech. 2013, 14 (1), 189-199

[118] Bartos, C.; Ambrus, R.; Sipos, P.; Budai-Szucs, M.; Csányi, E.; Gáspár, R.; Márki, Á.; Seres, A. B.; Sztojkov-Ivanov, A.; Horváth, T.; Szabó-Révész, P. Study of Sodium Hyaluronate-Based Intranasal Formulations Containing Micro- or Nanosized Meloxicam Particles. Int. J. Pharm. 2015, 491 (1-2), 198-207

[119] Anil, P.; Pravin, C.; Prashant, G.; Amol, P.; Prakash, B. Study the Effect of Surfactant Concentration and Ultrasonication Time on Aqueous Solubility, Particle Size and In-Vitro Drug Diffusion of Ezogabine Nanosuspension by 32 Factorial Designs. Br. Biomed. Bull. 2016, 4 (1), 15-26

[120] Dilpreet, S. Lipid Based Drug Delivery System: A Review. Int. J. Life Sci. Rev. 2015, 1 (5), 169-174

[121] Koroleva, M. Y.; Nagovitsina, T. Y.; Bidanov, D. A.; Gorbachevski, O. S.; Yurtov, E. V. Nano- and Microcapsules as Drug-Delivery Systems. Resour. Technol. 2016, 2 (4), 233-239

[122] Akbarzadeh, A.; Rezaei-Sadabady, R.; Davaran, S.; Joo, S. W.; Zarghami, N.; Hanifehpour, Y.; Samiei, M.; Kouhi, M.; Nejati-Koshki, K. Liposome: Classification, Preparation, and Applications. Nanoscale Res. Lett. 2013, 8 (1), 102

[123] Lian, T.; Ho, R. J. Y. Trends and Developments in Liposome Drug Delivery Systems. J Pharm Sci. 2001, 90 (6), 667680

[124] Kimelberg, H. K.; Mayhew, E. G.; Gregoriadis, G. Properties and Biological Effects of Liposomes and Their Uses in Pharmacology and Toxicology. Crit. Rev. Toxicol. 1978, 6 (1), 25-79

[125] Law, S. L.; Shih, C. L. Characterization of Calcitonin-Containing Liposome Formulations for Intranasal Delivery. $J$. Microencapsul. 2001, 18 (2), 211-221

[126] Law, S. L.; Huang, K. J.; Chou, V. H.; Cherng, J. Y. Enhancement of Nasal Absorption of Calcitonin Loaded in Liposomes. J. Liposome Res. 2001, 11 (2-3), 165-174

[127] Chen, M.; Li, X. R.; Zhou, Y. X.; Yang, K. W.; Chen, X. W.; Deng, Q.; Liu, Y.; Ren, L. J. Improved Absorption of Salmon Calcitonin by Ultraflexible Liposomes through Intranasal Delivery. Peptides. 2009, 30 (7), 1288-1295

[128] Maitani, Y.; Asano, S.; Takahashi, S.; Nakagaki, M.; Nagai, T. Permeability of Insulin Entrapped in Liposome through the Nasal Mucosa of Rabbits. Chem. Pharm. Bull. (Tokyo). 1992, 40 (6), 1569-1572

[129] Muramatsu, K.; Maitani, Y.; Takayama, K.; Nagai, T. The Relationship Between the Rigidity of the Liposomal Membrane and the Absorption of Insulin After Nasal Administration of Liposomes Modified with an Enhancer Containing Insulin in Rabbits. Drug Dev. Ind. Pharm. 1999, 25 (10), 1099-1105

[130] Jain, A. K.; Chalasani, K. B.; Khar, R. K.; Ahmed, F. J.; Diwan, P. V. Muco-Adhesive Multivesicular Liposomes as an Effective Carrier for Transmucosal Insulin Delivery. J. Drug Target. 2007, 15 (6), 417-427

[131] Fortuna, A.; Alves, G.; Serralheiro, A.; Sousa, J.; Falcão, A. Intranasal Delivery of Systemic-Acting Drugs: SmallMolecules and Biomacromolecules. Eur. J. Pharm. Biopharm. 2014, 88 (1), 8-27

[132] Migliore, M. M.; Vyas, T. K.; Campbell, R. B.; Amiji, M. M.; Waszczak, B. L. Brain Delivery of Proteins by the Intranasal Route of Administration : A Comparison of Cationic Liposomes Versus Aqueous Solution Formulations. J Pharm. Sci. 2010, 99 (4), 1745-1761

[133] Patel, G. B.; Zhou, H.; Ponce, A.; Chen, W. Mucosal and Systemic Immune Responses by Intranasal Immunization Using Archaeal Lipid-Adjuvanted Vaccines. Vaccine. 2007, 25 (51), 8622-8636

[134] de Haan, A. De; Geerligs, H. J.; Huchshorn, J. P.; Scharrenburg van, G.; Palache, A.; Wilsch, J. Mucosal Immunoadjuvant Activity of Liposomes : Induction of Systemic IgG and Secretory IgA Responses in Mice by 
Intranasal Immunization with an Influenza Subunit Vaccine and Coadministered Liposomes. Vaccine. 1995, 13 (2), $155-162$.

[135] Wong, J. P.; Cherwonogrodzky, J. W.; Di Ninno, V. L.; Stadnyk, L. L.; Knodel, M. H. Liposome Potentiation of Humoral Immune Response to Lipopolysaccharide and O-Polysaccharide Antigens of Brucella Abortus. Immunology. 1992, $77(1), 123-128$

[136] Wang, H.; Jiang, P.; Lin, S.; Lin, H.; Ou, K.; Deng, W.; Lee, L.; Huang, Y.; Liang, P.; Liu, D. Application of Galactose-Modified Liposomes as a Potent Antigen Presenting Cell Targeted Carrier for Intranasal Immunization. Acta Biomater. 2013, 9 (3), 5681-5688

[137] Khatri, K.; Goyal, A. K.; Gupta, P. N.; Mishra, N.; Mehta, A.; Vyas, S. P. Surface Modified Liposomes for Nasal Delivery of DNA Vaccine. Vaccine. 2008, 26 (18), 2225-2233

[138] Lu, Y.; Kawakami, S.; Yamashita, F.; Hashida, M. Development of an Antigen-Presenting Cell-Targeted DNA Vaccine against Melanoma by Mannosylated Liposomes. Biomaterials. 2007, 28 (21), 3255-3262

[139] Müller, R. Solid Lipid Nanoparticles (SLN) for Controlled Drug Delivery: A Review of the State of the Art. Eur. J. Pharm. Biopharm. 2000, 50 (1), 161-177

[140] Chavan, S. S.; Ingle, S. G.; Vavia, P. R. Preparation and Characterization of Solid Lipid Nanoparticle-Based Nasal Spray of Budesonide. Drug Deliv. Transl. Res. 2012, 402-408

[141] Singh, A. P.; Saraf, S. K.; Saraf, S. A. SLN Approach for Nose-to-Brain Delivery of Alprazolam. Drug Deliv. Transl. Res. 2012, 2 (6), 498-507

[142] Fatouh, A. M.; Elshafeey, A. H.; Abdelbary, A. Intranasal Agomelatine Solid Lipid Nanoparticles to Enhance Brain Delivery: Formulation, Optimization and in Vivo Pharmacokinetics. Drug Des. Devel. Ther. 2017, 11, 1815-1825

[143] Khan, A.; Imam, S. S.; Aqil, M.; Ahad, A.; Sultana, Y.; Ali, A.; Khan, K. Brain Targeting of Temozolomide via the Intranasal Route Using Lipid-Based Nanoparticles: Brain Pharmacokinetic and Scintigraphic Analyses. Mol. Pharm. 2016, 13 (11), 3773-3782

[144] Hommoss, G.; Pyo, S. M.; Müller, R. H. Mucoadhesive Tetrahydrocannabinol-Loaded NLC - Formulation Optimization and Long-Term Physicochemical Stability. Eur. J. Pharm. Biopharm. 2017, 117, 408-417

[145] Bagheri, A.; Chu, B. S.; Yaakob, H. Niosomal Drug Delivery Systems: Formulation, Preparation and Applications. World Appl. Sci. J. 2014, 32 (8), 1671-1685

[146] Kocbek, P.; Baumgartner, S.; Kristl, J. Preparation and evaluation of nanosuspensions for enhancing the dissolution of poorly soluble drugs. Int. J. Pharm. 2006, 312(1-2), 179-186

[147] Ravouru, N.; Kondreddy, P.; Korakanchi, D.; Haritha, M. Formulation and Evaluation of Niosomal Nasal Drug Delivery System of Folic Acid for Brain Targeting. Curr. Drug. Discov. Technol. 2013, 10 (4), 270-282

[148] Ammar, H. O.; Haider, M.; Ibrahim, M.; El Hoffy, N. M. In Vitro and in Vivo Investigation for Optimization of Niosomal Ability for Sustainment and Bioavailability Enhancement of Diltiazem after Nasal Administration. Drug Deliv. 2017, 24 (1), 414-421

[149] Cortesi, R.; Ravani, L.; Rinaldi, F.; Marconi, P.; Drechsler, M.; Manservigi, M.; Argnani, R.; Menegatti, E.; Esposito, E.; Manservigi, R. Intranasal Immunization in Mice with Non-Ionic Surfactants Vesicles Containing HSV Immunogens: A Preliminary Study as Possible Vaccine against Genital Herpes. Int. J. Pharm. 2013, 440 (2), 229-237

[150] Mason, T. G.; Wilking, J. N.; Meleson, K.; Chang, C. B.; Graves, S. M. Nanoemulsions: Formation, Structure, and Physical Properties. J. Phys. Condens. Matter. 2006, 18 (41), R635-R666

[151] Jaiswal, M.; Kumar, A.; Sharma, S. Nanoemulsions Loaded Carbopol@ 934 Based Gel for Intranasal Delivery of Neuroprotective Centella Asiatica Extract: In-Vitro and Ex-Vivo Permeation Study. J. Pharm. Investig. 2016, 46 (1), 79-89

[152] Comfort, C.; Garrastazu, G.; Pozzoli, M.; Sonvico, F. Opportunities and challenges for the nasal administration of nanoemulsions. Curr. Top. Med. Chem. 2015, 15 (4), 356-368

[153] Hosny, K. M.; Banjar, Z. M. The Formulation of a Nasal Nanoemulsion Zaleplon in Situ Gel for the Treatment of Insomnia. Expert. Opin. Drug. Deliv. 2013, 10 (8), 1033-1041

[154] Myc, A.; Kukowska-Latallo, J. F.; Bielinska, A. U.; Cao, P.; Myc, P. P.; Janczak, K.; Sturm, T. R.; Grabinski, M. S.; Landers, J. J.; Young, K. S.; Chang, J.; Hamouda, T.; Olszewski, M.A.; Baker, J.R., Jr. Development of Immune Response That Protects Mice from Viral Pneumonitis after a Single Intranasal Immunization with Influenza A Virus and Nanoemulsion. Vaccine. 2003, 21 (25-26), 3801-3814

[155] Lindell, D. M.; Morris, S. B.; White, M. P.; Kallal, L. E.; Lundy, P. K.; Hamouda, T.; Baker, J. R.; Lukacs, N. W. A Novel Inactivated Intranasal Respiratory Syncytial Virus Vaccine Promotes Viral Clearance without TH2 Associated Vaccine-Enhanced Disease. PLoS One. 2011, 6 (7)

[156] Bielinska, A. U.; Janczak, K. W.; Landers, J. J.; Markovitz, D. M.; Montefiori, D. C.; Baker, J. R. Nasal Immunization with a Recombinant HIV Gp120 and Nanoemulsion Adjuvant Produces Th1 Polarized Responses and Neutralizing Antibodies to Primary HIV Type 1 Isolates. AIDS Res. Hum. Retroviruses. 2008, 24 (2), 271-281

[157] Hamouda, T.; Chepurnov, A.; Mank, N.; Knowlton, J.; Chepurnova, T.; Myc, A.; Sutcliffe, J.; Baker, J. R. Efficacy, Immunogenicity and Stability of a Novel Intranasal Nanoemulsion-Adjuvanted Influenza Vaccine in a Murine Model. Hum. Vaccin. 2010, 6 (7), 585-594

[158] Azeem, A.; Rizwan, M.; Ahmad, F. J.; Iqbal, Z.; Khar, R. K.; Aqil, M.; Talegaonkar, S. Nanoemulsion Components 
Screening and Selection: A Technical Note. AAPS PharmSciTech. 2009, 10 (1), 69-76

[159] Sun, H.; Wei, C.; Liu, B.; Jing, H.; Feng, Q.; Tong, Y.; Yang, Y.; Yang, L.; Zuo, Q.; Zhang, Y.; Zou, Q.; Zeng, H. Induction of Systemic and Mucosal Immunity against Methicillin-Resistant Staphylococcus Aureus Infection by a Novel Nanoemulsion Adjuvant Vaccine. Int. J. Nanomedicine. 2015, 7275

[160] Quintanar-Guerrero, D.; Allémann, E.; Fessi, H.; Doelker, E. Preparation Techniques and Mechanisms of Formation of Biodegradable Nanoparticles from Preformed Polymers. Drug Dev. Ind. Pharm. 1998, 24 (12), 1113-1128

[161] Prego, C.; Torres, D.; Alonso, M. J. Chitosan Nanocapsules: A New Carrier for Nasal Peptide Delivery. J. Drug Deliv. Sci. Technol. 2006, 16 (5), 331-337

[162] Sallam, M. A.; Helal, H. M.; Mortada, S. M. Rationally Designed Nanocarriers for Intranasal Therapy of Allergic Rhinitis: Influence of Carrier Type on in Vivo Nasal Deposition. Int. J. Nanomedicine. 2016, 11, 2345-2357

[163] Clementino, A.; Batger, M.; Garrastazu, G.; Pozzoli, M.; Del Favero, E.; Rondelli, V.; Gutfilen, B.; Barboza, T.; Sukkar, M. B.; Souza, S.A.L.; Cantù, L.; Sonvico, F. The Nasal Delivery of Nanoencapsulated Statins- an Approach for Brain Delivery. Int. J. Nanomedicine. 2016, 11, 6575-6590

[164] Vicente, S.; Peleteiro, M.; Díaz-Freitas, B.; Sanchez, A.; González-Fernández, Á.; Alonso, M. J. Co-Delivery of Viral Proteins and a TLR7 Agonist from Polysaccharide Nanocapsules: A Needle-Free Vaccination Strategy. J. Control. Release. 2013, 172 (3), 773-781

[165]. Kumar, M; Mirsa, A.; Mishra, A. K.; Mishra, P.; Pathak, K. Intranasal nanoemulsion based brain targeting delivery system of risperidone. Int. J. Pharm. 2008, 358 (1-2), 285-291

[166] Kumar, M.; Misra, A.; Mishra, A. K.; Mishra, P.; Pathak, K. Mucoadhesive Nanoemulsion-Based Intranasal Drug Delivery System of Olanzapine for Brain Targeting. J. Drug. Target. 2008, 16 (10), 806-814

[167] Colombo, M.; Figueiró, F.; de Fraga Dias, A.; Teixeira, H. F.; Battastini, A. M. O.; Koester, L. S. Kaempferol-Loaded Mucoadhesive Nanoemulsion for Intranasal Administration Reduces Glioma Growth in Vitro. Int. J. Pharm. 2018, 543 (1-2), 214-223

[168] Abdou, E. M.; Kandil, S. M.; Miniawy, H. M. F. E. Brain Targeting Efficiency of Antimigrain Drug Loaded Mucoadhesive Intranasal Nanoemulsion. Int. J. Pharm. 2017, 529 (1-2), 667-677

[169]. Nasr, M. Development of an optimized hyaluronic acid-based lipidic nanoemulsion co-encapsulating two polyphenols for nose to brain delivery. Drug Deliv. 2016, 23 (4), 1444-1452

[170] Alsarra, I. A.; Hamed, A. Y.; Alanazi, F. K. Acyclovir Liposomes for Intranasal Systemic Delivery: Development and Pharmacokinetics Evaluation. Drug Deliv. 2008, 15 (5), 313-321

[171] Qiang, F.; Shin, H. J.; Lee, B. J.; Han, H. K. Enhanced Systemic Exposure of Fexofenadine via the Intranasal Administration of Chitosan-Coated Liposome. Int. J. Pharm. 2012, 430 (1-2), 161-166

[172] Nageeb El-Helaly, S.; Abd Elbary, A.; Kassem, M. A.; El-Nabarawi, M. A. Electrosteric Stealth Rivastigmine Loaded Liposomes for Brain Targeting: Preparation, Characterization, Ex Vivo , Bio-Distribution and in Vivo Pharmacokinetic Studies. Drug Deliv. 2017, 24 (1), 692-700

[173] Al Asmari, A. K.; Ullah, Z.; Tariq, M.; Fatani, A. Preparation, Characterization, and in Vivo Evaluation of Intranasally Administered Liposomal Formulation of Donepezil. Drug Des. Devel. Ther. 2016, 10, 205-215

[174] Chandra Bhatt, P.; Srivastava, P.; Pandey, P.; Khan, W.; Panda, B. P. Nose to Brain Delivery of Astaxanthin-Loaded Solid Lipid Nanoparticles: Fabrication, Radio Labeling, Optimization and Biological Studies. RSC Adv. 2016, 6 (12), $10001-10010$

[175] Li, J. C.; Zhang, W. J.; Zhu, J. X.; Zhu, N.; Zhang, H. M.; Wang, X.; Zhang, J.; Wang, Q. Q. Preparation and Brain Delivery of Nasal Solid Lipid Nanoparticles of Quetiapine Fumarate in Situ Gel in Rat Model of Schizophrenia. Int. J. Clin. Exp. Med. 2015, 8 (10), 17590-17600

[176] Zheng, X.; Shao, X.; Zhang, C.; Tan, Y.; Liu, Q.; Wan, X.; Zhang, Q.; Xu, S.; Jiang, X. Intranasal H102 PeptideLoaded Liposomes for Brain Delivery to Treat Alzheimer's Disease. Pharm. Res. 2015, 32 (12), 3837-3849

[177] Li, W.; Zhou, Y.; Zhao, N.; Hao, B.; Wang, X. Pharmacokinetic Behavior and Efficiency of Acetylcholinesterase Inhibition in Rat Brain after Intranasal Administration of Galanthamine Hydrobromide Loaded Flexible Liposomes. Environ. Toxicol. Pharmacol. 2012, 34 (2), 272-279

[178] Bender, T. S.; Migliore, M. M.; Campbell, R. B.; Gatley, S. J.; Waszczak, B. L. Intranasal administration of glialderived neurotrophic factor (GDNF) rapidly and significantly increases whole-brain gdnf level in rats. Neuroscience. 2015, 303, 569-576

[179] Migliore, M. M.; Ortiz, R.; Dye, S.; Campbell, R. B.; Amiji, M. M.; Waszczak, B. L. Neurotrophic and Neuroprotective Efficacy of Intranasal GDNF in a Rat Model of Parkinson's Disease. Neuroscience. 2014, 274, 11-23

[180] Yasir, M.; Sara, U.; Som, I. Haloperidol Loaded Solid Lipid Nanoparticles for Nose to Brain Delivery: Stability and In Vivo Studies. J. Nanomed. Nanotechnol. 2015, 01 (s7)

[181] Tiwari, S.; Goyal, A. K.; Mishra, N.; Vaidya, B.; Mehta, A.; Dube, D.; Vyas, S. P. Liposome in Situ Gelling System: Novel Carrier Based Vaccine Adjuvant for Intranasal Delivery of Recombinant Protein Vaccine. Procedia Vaccinol. 2009, 1 (1), 148-163 
[182] Ghaffar, K. A.; Marasini, N.; Giddam, A. K.; Batzloff, M. R.; Good, M. F.; Skwarczynski, M.; Toth, I. LiposomeBased Intranasal Delivery of Lipopeptide Vaccine Candidates against Group A Streptococcus. Acta Biomater. 2016, 41, $161-168$

[183] Tada, R.; Hidaka, A.; Iwase, N.; Takahashi, S.; Yamakita, Y.; Iwata, T.; Muto, S.; Sato, E.; Takayama, N.; Honjo, E.; Kiyono, H.; Kunisawa, J.; Aramaki, Y. Intranasal Immunization with Dotap Cationic Liposomes Combined with DCCholesterol Induces Potent Antigen-Specific Mucosal and Systemic Immune Responses in Mice. PLoS One. 2015, 10 (10), 1-21

[184] Rosada, R. S.; Torre, L.; Frantz, F. G.; Trombone, A. P.; Zárate-Bladés, C. R.; Fonseca, D. M.; Souza, P. R.; Brandão, I. T.; Masson, A. P.; Soares, É.G.; Ramos, S.G.; Faccioli, L.H.; Silva, C.L.; Santana, M.H.; Coelho-Castelo, A.A. Protection against Tuberculosis by a Single Intranasal Administration of DNA-Hsp65 Vaccine Complexed with Cationic Liposomes. BMC Immunol. 2008, 9 (1), 38

[185] Chen, K. H.; Di Sabatino, M.; Albertini, B.; Passerini, N.; Kett, V. L. The Effect of Polymer Coatings on Physicochemical Properties of Spray-Dried Liposomes for Nasal Delivery of BSA. Eur. J. Pharm. Sci. 2013, 50 (3-4), 312-322

[186] Kumar, M.; Kakkar, V.; Mishra, A. K.; Chuttani, K.; Kaur, I. P. Intranasal Delivery of Streptomycin Sulfate (STRS) Loaded Solid Lipid Nanoparticles to Brain and Blood. Int. J. Pharm. 2014, 461 (1-2), 223-233

[187] Singh, A.; Ubrane, R.; Prasad, P.; Ramteke, S. Preparation and Characterization of Rizatriptan Benzoate Loaded Solid Lipid Nanoparticles for Brain Targeting. Mater. Today Proc. 2015, 2 (9), 4521-4543

[188] Shah, B.; Khunt, D.; Bhatt, H.; Misra, M.; Padh, H. Intranasal Delivery of Venlafaxine Loaded Nanostructured Lipid Carrier: Risk Assessment and QbD Based Optimization. J. Drug Deliv. Sci. Technol. 2016, 33, 37-50

[189] Singh, S. K.; Dadhania, P.; Vuddanda, P. R.; Jain, A.; Velaga, S.; Singh, S. Intranasal Delivery of Asenapine Loaded Nanostructured Lipid Carriers: Formulation, Characterization, Pharmacokinetic and Behavioural Assessment. RSC Adv. 2016, 6 (3), 2032-2045

[190] Fonseca, F. N.; Betti, A. H.; Carvalho, F. C.; Gremião, M. P. D.; Dimer, F. A.; Guterres, S. S.; Tebaldi, M. L.; Rates, S. M. K.; Pohlmann, A. R. Mucoadhesive Amphiphilic Methacrylic Copolymer-Functionalized Poly( $\varepsilon$-Caprolactone) Nanocapsules for Nose-to-Brain Delivery of Olanzapine. J. Biomed. Nanotechnol. 2014, 11 (8), 1472-1481

[191] Vyshnavi, V.; Indira, S.; Prathima, S. Formulation and Evaluation of Nasal Niosomal in Situ Gels of Loratadine. Int. J. Pharm. Sci. Drug Res. 2015, 7 (1), 13-21

[192] Choi, C. S.; Kumar, P. Cationic cell-penetrating peptides as vehicles for siRNA delivery.Therapeutic Delivery. 2015, 6, 491-507

[193] Boche, M.; Pokharkar, V. Quetiapine Nanoemulsion for Intranasal Drug Delivery: Evaluation of Brain-Targeting Efficiency. AAPS PharmSciTech. 2017, 18 (3), 686-696

[194] Lalani, J.; Baradia, D.; Lalani, R.; Misra, A. Brain Targeted Intranasal Delivery of Tramadol: Comparative Study of Microemulsion and Nanoemulsion. Pharm. Dev. Technol. 2015, 20 (8), 992-1001

[195] Ahmad, N.; Ahmad, R.; Naqvi, A. A.; Alam, M. A.; Ashafaq, M.; Abdur Rub, R.; Ahmad, F. J. Intranasal Delivery of Quercetin-Loaded Mucoadhesive Nanoemulsion for Treatment of Cerebral Ischaemia. Artif. Cells, Nanomedicine Biotechnol. 2018, 46 (4), 717-729

[196] Ahmad, N.; Ahmad, R.; Alam, M. A.; Samim, M.; Iqbal, Z.; Ahmad, F. J. Quantification and Evaluation of Thymoquinone Loaded Mucoadhesive Nanoemulsion for Treatment of Cerebral Ischemia. Int. J. Biol. Macromol. 2016, $88,320-332$

[197] Mahajan, H. S.; Mahajan, M. S.; Nerkar, P. P.; Agrawal, A. Nanoemulsion-Based Intranasal Drug Delivery System of Saquinavir Mesylate for Brain Targeting. Drug Deliv. 2014, 21 (2), 148-154

[198] Mishra, D. K.; Kumar, A.; Raj, R.; Chaturvedi, A. Campula MCM Based Nanoemulsion for Intranasal Delivery Oa an Antidepressant. Bull. Pharm. Res. 2013, 3 (1), 34-39

[199] Yadav, S.; Gandham, S. K.; Panicucci, R.; Amiji, M. M. Intranasal Brain Delivery of Cationic NanoemulsionEncapsulated TNF $\alpha$ SiRNA in Prevention of Experimental Neuroinflammation. Nanomedicine Nanotechnology, Biol. Med. 2016, 12 (4), 987-1002

[200] Makidon, P. E.; Knowlton, J.; Groom, J. V.; Blanco, L. P.; LiPuma, J. J.; Bielinska, A. U.; Baker, J. R. Induction of Immune Response to the 17 KDa OMPA Burkholderia Cenocepacia Polypeptide and Protection against Pulmonary Infection in Mice after Nasal Vaccination with an OMP Nanoemulsion-Based Vaccine. Med. Microbiol. Immunol. 2010, 199 (2), 81-92

[201] Sravanthi, V.; Pallavi, M. C. P.; Bonam, S. R.; Sathyabama, S.; Sampath Kumar, H. M. Oleic Acid Nanoemulsion for Nasal Vaccination: Impact on Adjuvanticity Based Immune Response. J. Drug Deliv. Sci. Technol. 2015, 28, 56-63

[202] Das, S. C.; Hatta, M.; Wilker, P. R.; Myc, A.; Hamouda, T.; Neumann, G.; Baker, J. R.; Kawaoka, Y. Nanoemulsion W 805EC Improves Immune Responses upon Intranasal Delivery of an Inactivated Pandemic H1N1 Influenza Vaccine. Vaccine. 2012, 30 (48), 6871-6877

[203] Makidon, P. E.; Bielinska, A. U.; Nigavekar, S. S.; Janczak, K. W.; Knowlton, J.; Scott, A. J.; Mank, N.; Cao, Z.; Rathinavelu, S.; Beer, M. R.; Wilkinson, J. E.; Blanco, L.P; Landers, J. J; Baker, J.R. Jr. Pre-Clinical Evaluation of a Novel Nanoemulsion-Based Hepatitis B Mucosal Vaccine. PLoS One. 2008, 3 (8)

[204] Ali, J.; Ali, M.; Baboota, S.; Sahani, J. K.; Ramassamy, C.; Dao, L.; Bhavna. Potential of Nanoparticulate Drug 
Delivery Systems by Intranasal Administration. Curr. Pharm. Des. 2010, 16 (14), 1644-1653

[205] Soppimath, K.; Aminabhavi; Rudzinski WE, T.; Kulkarni AR. Biodegradable Polymeric Nanoparticles as Drug Delivery Devices. J. Control Release. 2001, 70, 1-20

[206] Pangestuti, R.; Kim, S. K. Neuroprotective Properties of Chitosan and Its Derivatives. Mar. Drugs 2010, 8 (7), 2117 2128

[207] Sharma, S.; Lohan, S.; Murthy, R. S. R. Formulation and Characterization of Intranasal Mucoadhesive Nanoparticulates and Thermo-Reversible Gel of Levodopa for Brain Delivery. Drug Dev. Ind. Pharm. 2014, 40 (7), 869-878

[208] Amidi, M.; Romeijn, S. G.; Borchard, G.; Junginger, H. E.; Hennink, W. E.; Jiskoot, W. Preparation and Characterization of Protein-Loaded N-Trimethyl Chitosan Nanoparticles as Nasal Delivery System. J. Control. Release. 2006, 111 (1-2), 107-116

[209] Imbimbo, B. P. Why Did Tarenflurbil Fail in Alzheimer's Disease? J. Alzheimer's Dis. 2009, 17 (4), 757-760

[210] Muntimadugu, E.; Dhommati, R.; Jain, A.; Challa, V. G. S.; Shaheen, M.; Khan, W. Intranasal Delivery of Nanoparticle Encapsulated Tarenflurbil: A Potential Brain Targeting Strategy for Alzheimer's Disease. Eur. J. Pharm. Sci. 2016, 92, 224-234

[211] Phua, K. K. L.; Staats, H. F.; Leong, K. W.; Nair, S. K. Intranasal MRNA Nanoparticle Vaccination Induces Prophylactic and Therapeutic Anti-Tumor Immunity. Sci. Rep. 2014, 4, 5128

[212] Matsuo, K.; Koizumi, H.; Akashi, M.; Nakagawa, S.; Fujita, T.; Yamamoto, A.; Okada, N. Intranasal Immunization with Poly $(\gamma$-Glutamic Acid) Nanoparticles Entrapping Antigenic Proteins Can Induce Potent Tumor Immunity. $J$. Control. Release. 2011, 152 (2), 310-316

[213] Van Woensel, M.; Wauthoz, N.; Rosière, R.; Mathieu, V.; Kiss, R.; Lefranc, F.; Steelant, B.; Dilissen, E.; Van Gool, S. W.; Mathivet, T.; Gerhardt, H.; Amighi, K.; DeVleeschouwer, S. Development of SiRNA-Loaded Chitosan Nanoparticles Targeting Galectin-1 for the Treatment of Glioblastoma Multiforme via Intranasal Administration. $J$. Control. Release. 2016, 227, 71-81

[214] Ma, M.; Cheng, Y.; Xu, Z.; Xu, P.; Qu, H.; Fang, Y.; Xu, T.; Wen, L. Evaluation of Polyamidoamine (PAMAM) Dendrimers as Drug Carriers of Anti-Bacterial Drugs Using Sulfamethoxazole (SMZ) as a Model Drug. Eur. J. Med. Chem. 2007, 42 (1), 93-98

[215] Lancelot, A.; Clavería-gimeno, R.; Velázquez-campoy, A.; Abian, O.; Serrano, J. L.; Sierra, T. Nanostructures Based on Ammonium-Terminated Amphiphilic Janus Dendrimers as Camptothecin Carriers with Antiviral Activity. Eur. Polym. J. 2017, 90 (March), 136-149

[216] Gillies, E. R.; Fréchet, J. M. J. Dendrimers and Dendritic Polymers in Drug Delivery. Drug Discov. Today. 2005, 10 (1), 35-43

[217] Svenson, S.; Tomalia, D. A. Dendrimers in Biomedical Applications - Reflections on the Field. Adv. Drug Deliv. Rev. 2005, 57 (15), 2106-2129

[218] Madaan, K.; Kumar, S.; Poonia, N.; Lather, V.; Pandita, D. Dendrimers in Drug Delivery and Targeting: DrugDendrimer Interactions and Toxicity Issues. J. Pharm. Bioallied Sci. 2014, 6 (3), 139-150

[219] Kim, I.-D.; Shin, J.-H.; Kim, S.-W.; Choi, S.; Ahn, J.; Han, P.-L.; Park, J.-S.; Lee, J.-K. Intranasal Delivery of HMGB1 SiRNA Confers Target Gene Knockdown and Robust Neuroprotection in the Postischemic Brain. Mol. Ther. 2012, 20 (4), 829-839

[220] Katare, Y. K.; Daya, R. P.; Sookram Gray, C.; Luckham, R. E.; Bhandari, J.; Chauhan, A. S.; Mishra, R. K. Brain Targeting of a Water Insoluble Antipsychotic Drug Haloperidol via the Intranasal Route Using PAMAM Dendrimer. Mol. Pharm. 2015, 12 (9), 3380-3388

[221] Dong, Z.; Katsumi, H.; Sakane, T.; Yamamoto, A. Effects of Polyamidoamine (PAMAM) Dendrimers on the Nasal Absorption of Poorly Absorbable Drugs in Rats. Int. J. Pharm. 2010, 393 (1-2), 244-252

[222] Duncan, R.; Izzo, L. Dendrimer Biocompatibility and Toxicity. Adv. Drug Deliv. Rev. 2005, 57 (15), 2215-2237

[223] Chauhan, A. S.; Jain, N. K.; Diwan, P. V. Pre-Clinical and Behavioural Toxicity Profile of PAMAM Dendrimers in Mice. Proc. R. Soc. A. 2010, 466, 1535-1550

[224] Win-Shwe, T.-T.; Sone, H.; Kurokawa, Y.; Zeng, Y.; Zeng, Q.; Nitta, H.; Hirano, S. Effects of PAMAM Dendrimers in the Mouse Brain after a Single Intranasal Instillation. Toxicol. Lett. 2014, 228 (3), 207-215

[225] Baltzley, S.; Mohammad, A.; Malkawi, A. H.; Al-Ghananeem, A. M. Intranasal Drug Delivery of Olanzapine-Loaded Chitosan Nanoparticles. AAPS PharmSciTech. 2014, 15 (6), 1598-1602

[226] Bhavna; Md, S.; Ali, M.; Ali, R.; Bhatnagar, A.; Baboota, S.; Ali, J. Donepezil Nanosuspension Intended for Nose to Brain Targeting: In Vitro and in Vivo Safety Evaluation. Int. J. Biol. Macromol. 2014, 67, 418-425

[227] Maurya, P.; Mittal, A.; Sharma, K.; Alam, S. Fabrication of Acetazolamide Loaded Nasal Nanosuspension : An in Vitro and Ex Vivo Characterization. Analele Univ. "Dunărea Jos" Galaţi. 2013, 17 (1), 93-105

[228] Seju, U.; Kumar, A.; Sawant, K. K. Development and Evaluation of Olanzapine-Loaded PLGA Nanoparticles for Noseto-Brain Delivery: In Vitro and in Vivo Studies. Acta Biomater. 2011, 7 (12), 4169-4176

[229] Sharma, D.; Maheshwari, D.; Philip, G.; Rana, R.; Bhatia, S.; Singh, M.; Gabrani, R.; Sharma, S. K.; Ali, J.; Sharma, R. 
K.; Dang, S. Formulation and Optimization of Polymeric Nanoparticles for Intranasal Delivery of Lorazepam Using Box-Behnken Design: In Vitro and in Vivo Evaluation. Biomed Res. Int. 2014, 2014

[230] Bi, C. C.; Wang, A. P.; Chu, Y. C.; Liu, S.; Mu, H. J.; Liu, W. H.; Wu, Z. M.; Sun, K. X.; Li, Y. X. Intranasal Delivery of Rotigotine to the Brain with Lactoferrin-Modified PEG-PLGA Nanoparticles for Parkinson's Disease Treatment. Int. J. Nanomedicine. 2016, 11, 6547-6559

[231] Cheng, Q.; Feng, J.; Chen, J.; Zhu, X.; Li, F. Brain Transport of Neurotoxin-I with PLA Nanoparticles through Intranasal Administration in Rats: A Microdialysis Study. Biopharm. Drug Dispos. 2008, 29 (8), 431-439

[232] Al-Ghananeem, A. M.; Saeed, H.; Florence, R.; Yokel, R. a; Malkawi, A. H. Intranasal Drug Delivery of DidanosineLoaded Chitosan Nanoparticles for Brain Targeting; an Attractive Route against Infections Caused by AIDS Viruses. $J$. Drug Target. 2010, 18 (5), 381-388

[233] Alex, A. T.; Joseph, A.; Shavi, G.; Rao, J. V.; Udupa, N. Development and Evaluation of Carboplatin-Loaded PCL Nanoparticles for Intranasal Delivery. Drug Deliv. 2014, 1-10

[234] Elnaggar, Y. S. R.; Etman, S. M.; Abdelmonsif, D. A.; Abdallah, O. Y. Intranasal Piperine-Loaded Chitosan Nanoparticles as Brain-Targeted Therapy in Alzheimer's Disease: Optimization, Biological Efficacy, and Potential Toxicity. J. Pharm. Sci. 2015, 104 (10), 3544-3556

[235] Zhang, C.; Chen, J.; Feng, C.; Shao, X.; Liu, Q.; Zhang, Q.; Pang, Z.; Jiang, X. Intranasal Nanoparticles of Basic Fibroblast Growth Factor for Brain Delivery to Treat Alzheimer's Disease. Int. J. Pharm. 2014, 461 (1-2), 192-202

[236] Mittal, D.; Md, S.; Hasan, Q.; Fazil, M.; Ali, A.; Baboota, S.; Ali, J. Brain Targeted Nanoparticulate Drug Delivery System of Rasagiline via Intranasal Route. Drug Deliv. 2016, 23 (1), 130-139

[237] EMA, 2014. Human Regulatory, Quality By Design, Guidance Documents. Http:// www.ema.europa.eu/ema/index.jsp?curl=pages/regulation/document_listing/ document_listing_000162.jsp\&mid=WC0b01ac058076ed73 (Accessed Jul 24,2017).

[238] FDA Guidance for Industry: Nasal Spray and Inhalation Solution, Suspension, and Spray Drug Products. http://www.gmp-compliance.org/guidemgr/files/4234FNL.PDF (Accessed Jul 24,2017).

[239] FDA. Guidance for Industry Metered Dose Inhaler (MDI) and Dry Powder Inhaler (DPI) Drug Products. 1998, No. October, 1-65. Https://elsmar.com/elsmarqualityforum/attachments/mdi-dpis-fda-guideline-pdf.14553/. (Accessed Jul 24,2017).

[240] Sangshetti, J. N.; Deshpande, M.; Zaheer, Z.; Shinde, D. B.; Arote, R. Quality by Design Approach: Regulatory Need. Arab. J. Chem. 2017, 10, S3412-S3425

[241] Pallagi, E.; Ambrus, R.; Szabó-Révész, P.; Csóka, I. Adaptation of the Quality by Design Concept in Early Pharmaceutical Development of an Intranasal Nanosized Formulation. Int. J. Pharm. 2015, 491 (1-2), 384-392

[242] Shah, B.; Khunt, D.; Bhatt, H.; Misra, M.; Padh, H. Application of Quality by Design Approach for Intranasal Delivery of Rivastigmine Loaded Solid Lipid Nanoparticles: Effect on Formulation and Characterization Parameters. Eur. J. Pharm. Sci. 2015, 78, 54-66

[243] Chudiwal, S. S.; Dehghan, M. H. G. Quality by Design (QbD) Approach for Design and Development of Drug-Device Combination Products: A Case Study on Flunisolide Nasal Spray. Pharm. Dev. Technol. 2016, 1-10

[244] Sinsuebpol, C.; Chatchawalsaisin, J.; Kulvanich, P. Preparation and in Vivo Absorption Evaluation of Spray Dried Powders Containing Salmon Calcitonin Loaded Chitosan Nanoparticles for Pulmonary Delivery. Drug Des. Devel. Ther. 2013, 7, 861-873

[245] Djupesland, P. G. Nasal Drug Delivery Devices: Characteristics and Performance in a Clinical Perspective-a Review. Drug Deliv. Transl. Res. 2013, 3 (1), 42-62

[246] Trows, S.; Wuchner, K.; Spycher, R.; Steckel, H. Analytical Challenges and Regulatory Requirements for Nasal Drug Products in Europe and the U.S. Pharmaceutics. 2014, 6 (2), 195-219

[247] Yanez, A.; Dimitroff, A.; Bremner, P.; Rhee, C.-S.; Luscombe, G.; Prillaman, B. A.; Johnson, N. A Patient Preference Study That Evaluated Fluticasone Furoate and Mometasone Furoate Nasal Sprays for Allergic Rhinitis. Allergy Rhinol. 2016, 7, 1-6

[248] Hellings, P. W.; Dobbels, F.; Denhaerynck, K.; Piessens, M.; Ceuppens, J. L.; De Geest, S. Explorative Study on Patient's Perceived Knowledge Level, Expectations, Preferences and Fear of Side Effects for Treatment for Allergic Rhinitis. Clin. Transl. Allergy. 2012, 2 (1), 9

[249] Chao, J.; Nau, D. P.; Aikens, J. E. Patient-Reported Perceptions of Side Effects of Antihyperglycemic Medication and Adherence to Medication Regimens in Persons with Diabetes Mellitus. Clin. Ther. 2007, 29 (1), 177-180

[250] Fromer, L. M.; Ortiz, G. R.; Dowdee, A. M. Assessment of Patient Attitudes About Mometasone Furoate Nasal Spray: The Ease-of-Use Patient Survey. World Allergy Organ. J. 2008, 1 (9), 156-159

[251] U.S. Food and Drug Administration. Guidance for Industry. Integration of Dose-Counting Mechanisms into MDI Drug Products. 2003. March. https://www.fda.gov/regulatory-information/search-fda-guidance-documents/integration-dosecounting-mechanisms-mdi-drug-products. (Accessed Jul 24,2017)

[252] European medicines agency. Outcome Report on Pilot to Involve Patients in Benefit / Risk Discussions at CHMP Meetings. 2017, 44 (March). https://www.ema.europa.eu/en/documents/report/outcome-report-pilot-involve-patientsbenefit/risk-discussions-chmp-meetings_en.pdf. (Accessed Jul 24,2017) 
